\title{
Asymmetries in the equatorial electrojet around N-E Brazil sector
}

\author{
R. G. Rastogi ${ }^{1}$ and N. B. Trivedi ${ }^{2}$ \\ ${ }^{1}$ Physical Research Laboratory, Ahmedabad 380009, India \\ ${ }^{2}$ Observatorio Magnetico, 89 Madruga, Vassouras, Brazil
}

Received: 21 September 2007 - Revised: 13 December 2008 - Accepted: 7 January 2009 - Published: 12 March 2009

\begin{abstract}
The paper examines the data of geographic northward $(\mathrm{X})$, eastward $(\mathrm{Y})$ and vertical $(\mathrm{Z})$ components of the magnetic field from a dense array of 26 vector magnetometers operated in N-NE Brazil from November 1990 to March 1991. As expected, the daily variation of $\mathrm{X}$ showed a minor maximum around 03:00-04:00 LT and a major maximum around 12:00 LT. The daily range of $\Delta \mathrm{Y}$ showed a strong minimum around noon at all stations. The combined $\Delta \mathrm{Y}$ and $\Delta \mathrm{X}$ indicated the direction of the equatorial electrojet currents to be flowing along $25^{\circ}$ north of east at the centre and $20^{\circ}$ north of east at the edges of the equatorial electrojet (EEJ) belt. The centre of the EEJ as defined by the zero intercept of the $\mathrm{Z}$ versus latitude was found to be near $1.0^{\circ} \mathrm{S}$ dip latitude. The electrojet current was stronger in the northern half than in the southern half of the electrojet belt. These anomalies are suggested to be due to the abnormal distribution of the mean magnetic field in this region.
\end{abstract}

Keywords. Geomagnetism and paleomagnetism (Time variations, diurnal to secular) - Ionosphere (Electric fields and currents; Equatorial ionosphere)

\section{Background of the present study}

Following the study by Schuster $(1889,1908)$ several analyses of the diurnal variation of geomagnetic field have been made. The best known model for the global ionospheric current system has been that of Chapman (1919). It was envisaged that the lunar and solar tidal oscillations of the upper atmosphere generate winds in the upper atmosphere blowing ionized gas across the geomagnetic field creating an electric field as a result of which electric currents flow.

Correspondence to: R. G. Rastogi

(profrgrastogi@yahoo.com)
McNish (1937) described the famous Huancayo anomaly; the daily range of the horizontal component of the magnetic field was anomalously larger than anywhere in the world. He suggested that in South America, the magnetic equator departs considerably from the geographic equator and the electric fields induced in the middle and high latitudes assist the dynamo induced electric fields and cause enhanced current flow.

The most important observations of the equatorial magnetic field variation was the result of the ground survey by Giesecke (quoted in Chapman, 1951) at 14 stations in Peru during the period September to November 1949. The daily range of $H$ slowly increased from $7^{\circ} \mathrm{S}$ latitude to a peak at $13^{\circ} \mathrm{S}$, with a ratio of about 2 . Chapman (1951) estimated the width of this kind of abnormality to be $10^{\circ}$ (about $1100 \mathrm{~km}$ ). Egedal (1947) showed that when the daily range of $H$ at the equatorial and low latitude stations then available are plotted against the magnetic dip at the place, a sharp narrow peak of enhanced range of $H$ is observed over the equator. Chapman (1951) interpreted this as to be due to a band of current flowing eastward during the daytime hours in the ionosphere $(100 \mathrm{~km})$ and named it EQUATORIAL ELECTROJET (EEJ).

This "Huancayo Anomaly" presented a serious problem in assuming a narrow belt of abnormally large wind velocity to generate a large electro-motive force for the EEJ. The problem was solved considering the special feature of magnetic and electric fields being orthogonal to the vertical distribution of electron density gradient, the collisional and gyrofrequencies in the equatorial dynamo region. At the magnetic equator, the dynamo electric field during the daytime is primarily eastward and the magnetic field is northward, orthogonal to the electric field. The dynamo region is bounded by a non-conducting atmosphere below $70 \mathrm{~km}$ and by the effectively collision less plasma above $140 \mathrm{~km}$. The electrons within $70-140 \mathrm{~km}$ drift upwards relative to the ions causing a vertical Hall polarization field. Baker and Martyn (1953)

Published by Copernicus Publications on behalf of the European Geosciences Union. 


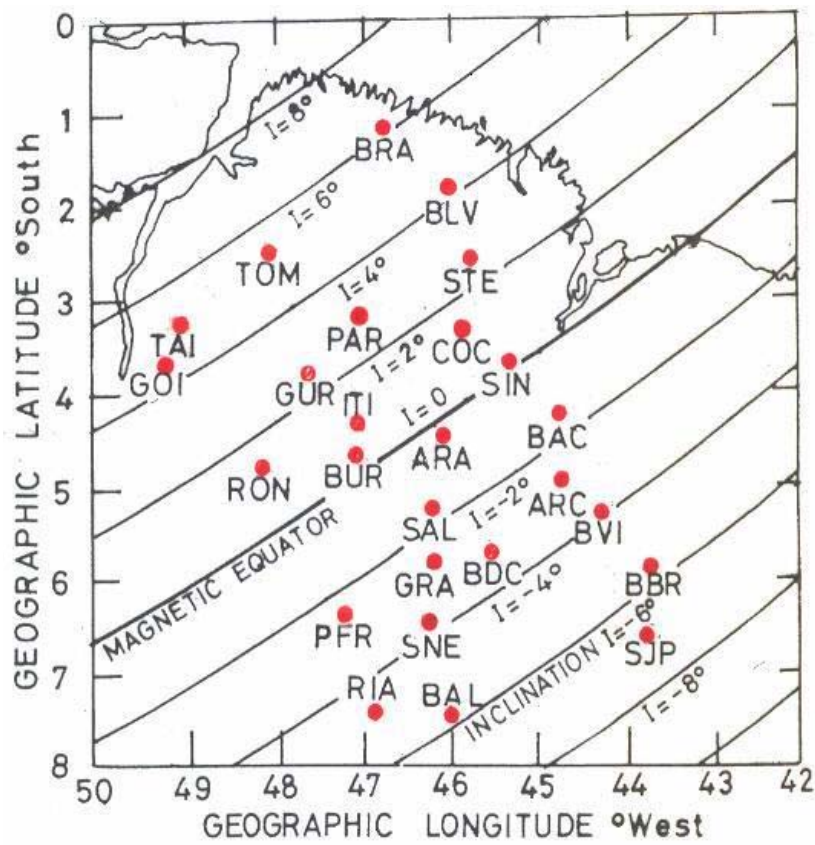

Fig. 1. Map showing the geographic locations of the stations whose data are used for analysis. The lines of constant "Inclination" are also indicated.

suggested that this vertical Hall polarization field causes an additional eastward current, which can be seen as an abnormal increase of the eastward Cowling conductivity. They also explained that beyond $3^{\circ}$ from the dip equator the polarization field leaks away along the inclined magnetic lines of force and the enhanced Cowling conductivity exists only within a narrow belt of $\pm 3^{\circ}$ dip latitude. The polarization field associated with EEJ now has assumed great importance as it controls the production and distribution of ionospheric E-region irregularities, spread $\mathrm{F}$, the distribution of ionospheric plasma over a large altitude and latitude range (Rastogi, 1989). With the operation of new magnetic stations at equatorial latitudes in different longitudes during the International Geophysical Year (IGY), Rastogi (1962) found that the strength of electrojet current is largest at Huancayo in a region of low background magnetic field intensity and is smallest in Trivandrum a region of high magnetic field. $\mathrm{He}$ also suggested that the Cowling conductivity may be inversely related to the mean magnetic field intensity.

It was realized that the EEJ is just a modification of the mid-latitude Sq current system by the narrow latitude belt of enhanced ionospheric conductivity. James et al. (1996) studied the day-to-day variability in $\mathrm{Sq}(\mathrm{H})$ at thirteen stations confined within a narrow longitude belt along the IndoRussian sector spread from equator to about $60^{\circ} \mathrm{N}$ dip latitude. Using the correlation coefficients of $\mathrm{Sq}(\mathrm{H})$ between each pair of stations, they identified three latitude zones, where correlations are very high (i) the equatorial latitude; (ii) mid-latitudes between EEJ and Sq focus and (iii) latitudes poleward of $\mathrm{Sq}$ focus. They suggested that the observed daily range in the $\mathrm{H}$ field for each day was the result of interaction of these three current systems. Thus, any critical study of the EEJ should be supported by a proper network of off-EEJ stations in the same longitude sector.

The densest array of vector magnetometers was operated in N-NE Brazil from November 1990 to March 1991 (Rigoti et al., 1999). The location of the field stations are indicated in the map shown in Fig. 1 and the coordinates of the stations are listed in Table 1. the array was designed to be roughly rectangular with the long side perpendicular to the dip equator. The average spacing was approximately $100 \mathrm{~km}$ and the area covered extended from $0^{\circ}$ to $8^{\circ} \mathrm{S}$ and $43^{\circ}$ to $49^{\circ} \mathrm{W}$. The iso-dip lines shown in the figure are taken from the survey map provided by Muniz Barretto, director of Observatorio Nacional, Rio de Janeiro. It is to be noted that Buriticupa (BUR) and Santa Ines (SIN) were the two stations very close to the magnetic equator. The stations farthest from the magnetic equator were S. J. dos Patos (SJP) in the south and Braganca (BRA) in the north. The equipment from ACA was uprooted by a farm machine before the programmed starting date. The declination data from Tatuoca and Natal were still not available and are not included in the analysis. Thus, we have been left with data from 26 stations only.

This paper is an attempt to understand the micro scale variations of EEJ in a longitude sector in which the magnetic meridian departs appreciably from the geographic meridian.

\section{Models of equatorial electrojet}

\subsection{Line current model}

Chapman (1951) first considered the magnetic field produced by an infinitely long straight horizontal current flowing above a plane Earth. If the total strength of the current $\mathrm{C}$ emu is flowing eastward, perpendicular to the magnetic meridian at a height " $h$ ", it can be shown that the magnetic field with horizontal $(\mathrm{H})$ and vertical $(\mathrm{Z})$ components produced a distance " $x$ " along the magnetic meridian are given by

$$
\begin{aligned}
& H=\frac{2 C h}{x^{2}+h^{2}} \\
& Z=-\frac{2 C x}{x^{2}+h^{2}}
\end{aligned}
$$

and

$$
\frac{Z}{H}=\frac{x}{h}
$$

Let $\mathrm{Ho}(=2 \mathrm{C} / h)$ be the value of $H$ at $x=0$. Then, elsewhere

$$
H x=H_{o} \frac{h^{2}}{x^{2}+h^{2}} \quad \text { and } \quad Z x=H_{o} \frac{x \cdot h}{x^{2}+h^{2}}
$$


LINE CURRENT MODEL

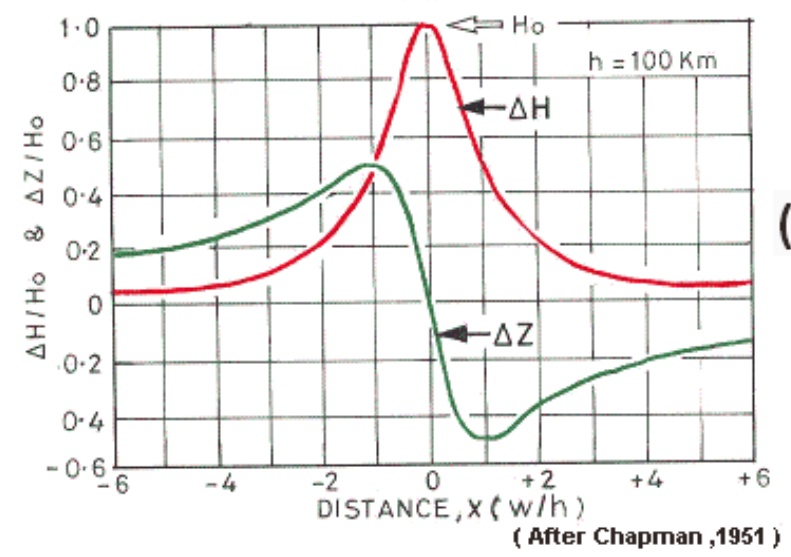

Fig. 2a. The variation of the horizontal $(\mathrm{H})$ and vertical $(\mathrm{Z})$ magnetic field components at ground due to an infinite straight horizontal electric current flowing at a height $h$ above the plane Earth; the ordinates represent fraction of Ho, the surface field directly below the current, the abscissa are expressed an terms of " $h$ " as unit.

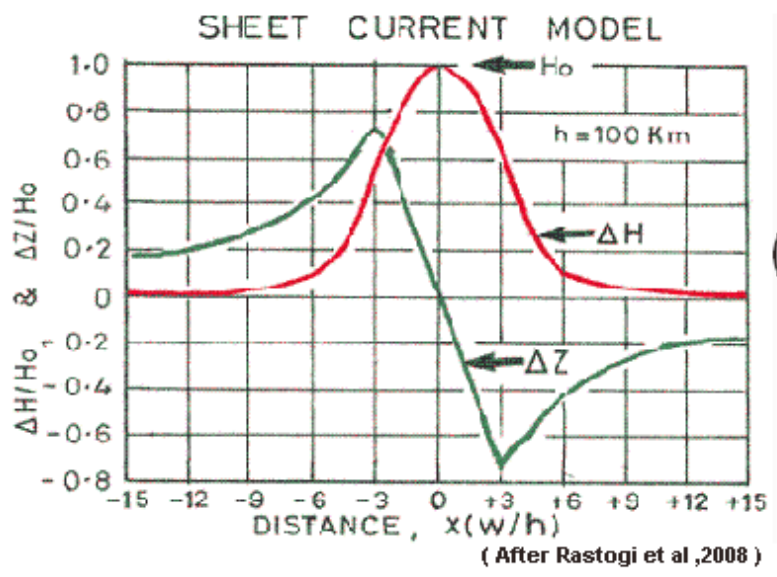

(b)

Fig. 2b. The latitude variation of $\mathrm{H}$ and $\mathrm{Z}$ components of the surface field of a horizontal band of eastward current of semi-width " $w$ " at a height of $h$ above the plane Earth (after Rastogi et al., 2008).

The distribution of $H$ and $Z$ with respect to $x$ is shown in Fig. 2a adopted from Fig. 7 in Chapman (1951). The peak value of $H=\mathrm{Ho}$ at $x=0$ decreases progressively with increasing $x$, being equal to 0.5 Ho at $x= \pm h$ and falls away to onetenth of Ho at $x / h= \pm 3$. The value of $Z$ is zero at $x=0$ and has a negative value in the north and positive values in the south of the axis of the current. $Z$ reaches the maximum value of 0.5 Ho at $x=h, 0.4 \mathrm{Ho}$ at $x=2 \mathrm{~h}, 0.3 \mathrm{Ho}$ at $x=3 \mathrm{~h}$.

\subsection{Ribbon (sheet) of constant intensity model}

The next step towards a more realistic electrojet current is to treat the current distribution over a ribbon, still flowing eastward to and from infinity. A simple integration of the

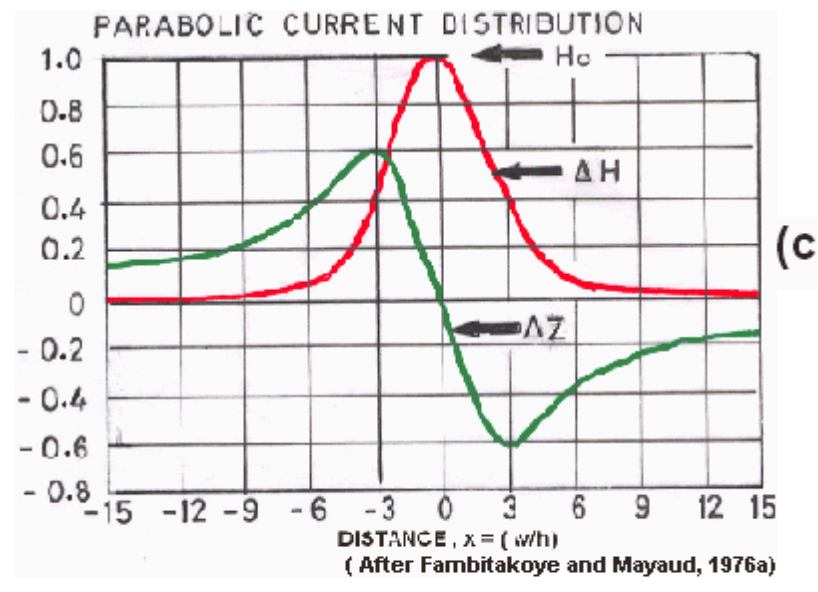

Fig. 2c. The latitudinal variation of $\mathrm{H}$ and $\mathrm{Z}$ components of the surface field of a horizontal band of eastward current of parabolic cross section intensity (after Fambitakoya and Mayaud, 1976).

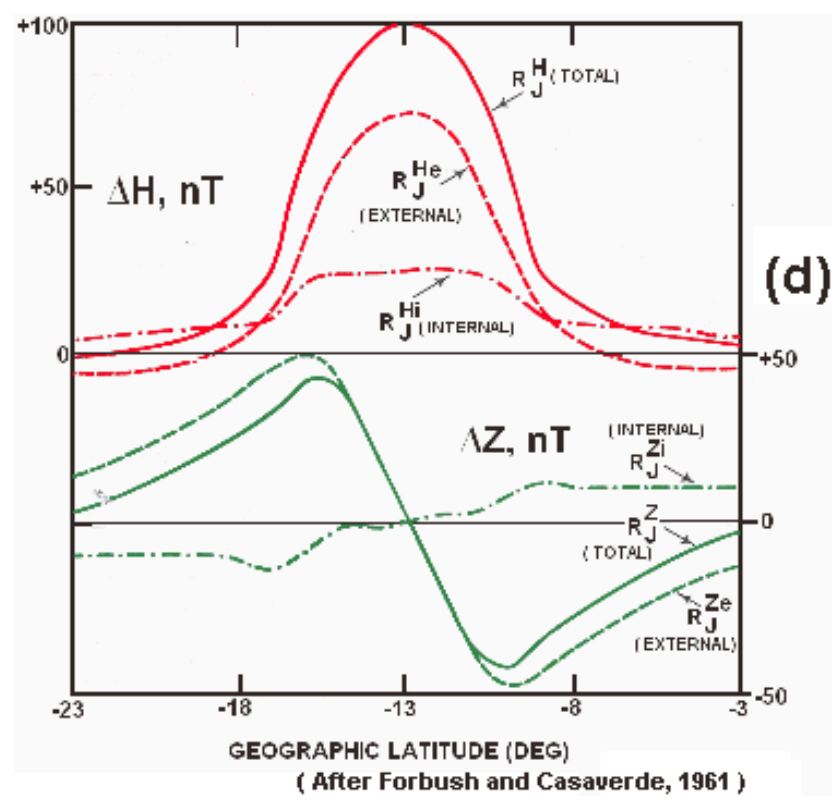

Fig. 2d. Latitudinal profiles of external, internal and total parts of $\Delta H$ and $\Delta Z$ for the Peruvian chain of stations during 1GY-1GC (after Forbush and Casaverde, 1961).

results for $H$ and $Z$ for a linear current gives the following values at a distance $x$ south of the axis of the band current.

$$
\begin{aligned}
& H=\frac{C}{w} \tan ^{-1} \frac{2 w h}{h^{2}+x^{2}-w^{2}} \\
& Z=-\frac{C}{2 w} \ln \frac{(x+w)^{2}+h^{2}}{(x-w)^{2}+h^{2}}
\end{aligned}
$$

The value of $H$ immediately below the axis of the band current is now $(\mathrm{Cw}) \tan ^{-1} 2 \mathrm{wh} /\left(h^{2}-w^{2}\right)$ or $(2 \mathrm{C} / \mathrm{w}) \tan ^{-1} \mathrm{w} / \mathrm{h}$ 
where $k=\mathrm{w} / \mathrm{h}$ in terms of Ho for linear current $(w=0)$, writing $w / h=k$

$$
H o(k) / H o=(1 / 2 k) \tan ^{-1} 2 k /\left(1-k^{2}\right)=\left(\tan ^{-1} k\right) / k
$$

The ratio of $\operatorname{Ho}(k) /$ Ho for $k=1,2,3$ respectively are 0.79 , 0.55 and 0.42 . The $\mathrm{H}$ curve has a lower peak, the more distributed current $\mathrm{C}$; that is, as $k$ increases, the $\mathrm{H}$ curve becomes flatter. The value of $x / h$ for which the curve falls to one tenth its maximum ordinate are 3.6, 4.6 and 5.6, respectively as against 3.0 for the line current $C$.

As regards $Z$, it is zero under the band axis and attains its maximum value when

$z_{\max }^{2}=h^{2}+w^{2}$

also

$\frac{Z_{\max }}{H_{\max }}=\frac{\ln \left[k+\left(1+k^{2}\right)^{1 / 2}\right]}{2 \tan ^{-1} k}$

For $w / h=1,2,3$ the respective value of $Z_{\max } / H_{\max }$ are 0.56 , 0.65 and 0.73 . As $w / h$ increases from 0 to 3 , the initial slope and the maximum of the $\mathrm{Z}$ curve decrease.

Figure $2 \mathrm{~b}$ shows the variation of $\mathrm{H}$ and $\mathrm{Z}$ with distance, $x$, from the centre of a band current of semi-width $w=300 \mathrm{~km}$ flowing eastward at a height of $100 \mathrm{~km}$.

\subsection{Current ribbon of parabolic intensity model}

Next, simplest case of a distributed band of unidirectional current is that in which the current intensity varies parabolically across the band, if Io is the maximum current intensity at the centre of the current band and $2 w$ is the width of the band

$C=C_{o}\left(1-x^{2} / c^{2}\right)$

where $C_{x}$ denotes the current intensity at the distance of $x$ from the band axis. Chapman (1951) gave the expression for the latitudinal variation of $H$ as

$\frac{H}{H_{o}}=\frac{3}{2} \frac{h^{2}}{x^{3}}\left[\frac{x^{2}+h^{2}}{h} \tan ^{-1} \frac{x}{h}-x\right]$

The field intensity $\mathrm{H} / \mathrm{H}_{0}=0.84$ under the band centre compared to the value of 0.78 under the uniform band model. Naturally the field intensity under the band centre in the present "parabolic" case is greater than in the case of uniform sheet though less than the line current case. Figure 2c shows the latitudinal variation of $H$ and $Z$ based on the cross equatorial chain of stations in Central Africa (After Fambitakoye and Mayaud, 1976).

\subsection{Current ribbon of fourth degree intensity model}

Fambitakoye and Mayaud (1976) considered a current distribution given by the expression:

$I x=I o\left(1-\frac{x^{2}}{w^{2}}\right)^{m}$ $-w \leq x \leq w$

where $I o$ is the current density at the centre of a ribbon whose half width is $w$ and the length is infinite. The ribbon is assumed to be infinitely thin and located at a height $h$ of $105 \mathrm{~km}$. When $m=2$; then the term $(x / w)$ rises up to the fourth degree. With $m=1$ (or $m=0$ ), one would have a "parabolic" (or uniform) distribution. When analyzing magnetic effects of the fourth degree current distribution by a parabolic (or uniform) distribution, ratio of the width thus obtained with respect to the width of fourth degree distribution is 0.82 (or 0.64 ).

\subsection{Current ribbon of continuous distribution of cur- rent density model}

Onwumechilli (1967) introduced a two-dimensional current distribution model for EEJ in which the current at any point $(\mathrm{x}, \mathrm{z})$ is given by

$I=I_{o} \frac{a^{2}\left(a^{2}+\alpha x^{2}\right)}{\left(a^{2}+x^{2}\right)^{2}} \frac{b^{2}\left(b^{2}+\beta z^{2}\right)}{\left(b^{2}+z^{2}\right)^{2}}$

where $I o$ is the intensity at $x=0, z=0 ; a$ and $b$ are constant scale lengths along $x$ and $z$, respectively; and $\alpha, \beta$ are dimensionless constants controlling the distribution of current along $\mathrm{x}$ and $\mathrm{z}$ respectively. For $\alpha \geq 0$ the current is unidirectional eastward but if $\alpha<0$, westward (reversed) current flow on the flanks of the magnetic dip equator.

\subsection{Electrojet model with a return flow of current}

Chapman (1951) considered the effects due to the return flow of the overhead current as consisting of one or more horizontal line currents of infinite length, parallel to the primary current, and together carrying a total current $-C$. Considering the return flow to consist of two equal current each $-1 / 2 C$ at height $h$ and at distance $\pm f h$ north and south of the primary current. In this case the combined direct external field $H$ of the flow $C$ and two return current $-1 / 2 C$ immediately below the current $C$ is $(2 C / h) f^{2} /\left(f^{2}+1\right)$; if $f=1,2,3$, respectively, this is $0.5 ; 0.8$ and 0.9 times $(2 C / h)$. For $f=1, H$ is at most only $1 / 2$. Ho and extends over a distance less than " $h$ " north and south of the current $C$ after which it is reversed. The $\mathrm{Z}$ field is everywhere numerically less than of the current $C$ alone. Thus, the magnitude and the distance of the return current can seriously distort the latitudinal variation of $H$ at ground.

\subsection{Effect of induced current due to EEJ}

Chapman (1951) considered the effect of current induced in the Earth by assuming of an Earth of non-conducting down to a certain depth $h^{1}$ and then below that it has infinite conductivity. The image current would be at the depth $h+h^{1}$ below the Earth's surface and would produce a field at the surface of the Earth whose horizontal component is the same as due 
Table 1. Coordinates and magnetic parameters of the stations.

\begin{tabular}{|c|c|c|c|c|c|c|c|}
\hline Station & Code & Lat. deg & Long. ${ }^{\circ} \mathrm{W}$ & Dip lat & $\mathrm{X}, \mathrm{nT}$ & $\mathrm{Y}, \mathrm{nT}$ & $\mathrm{Z}, \mathrm{nT}$ \\
\hline Natal & NAT & -5.8 & 35.2 & -7.8 & 23428 & -9493 & -7078 \\
\hline S. J. dos Patos & SJP & -6.5 & 43.8 & -3.4 & 24013 & -9027 & -3040 \\
\hline Balsas & BAL & -7.4 & 46.0 & -2.9 & 23705 & -8943 & -3709 \\
\hline Buriti Bravo & BBR & -5.9 & 43.8 & -2.8 & 24203 & -9080 & -2584 \\
\hline Riachao & RIA & -7.3 & 46.8 & -2.4 & 24108 & -8544 & -2130 \\
\hline Boa Vista & BVI & -5.2 & 44.3 & -2.0 & 24470 & -9082 & -1779 \\
\hline Serra Negra & SNE & -6.4 & 46.2 & -1.9 & 24306 & -8723 & -1738 \\
\hline Barra do Corda & $\mathrm{BDC}$ & -5.6 & 45.3 & -1.7 & 24448 & -8922 & -1573 \\
\hline Gov. Archer & ARC & -4.9 & 44.4 & -1.6 & 24570 & -9094 & -1489 \\
\hline Grajau & GRA & -5.8 & 46.2 & -1.4 & 24482 & -8777 & -1270 \\
\hline Porto Franco & PFR & -6.3 & 47.2 & -1.3 & 24452 & -8576 & -1161 \\
\hline Santa Luzia & SAL & -5.2 & 46.1 & -0.9 & 24645 & -8844 & -845 \\
\hline Bacabal & BAC & -4.2 & 44.8 & -0.8 & 24814 & -9099 & -716 \\
\hline Arame & ARA & -4.4 & 46.1 & -0.2 & 24872 & -8909 & -200 \\
\hline Buriticupa & BUR & -4.6 & 46.9 & 0.1 & 24891 & -8773 & 49 \\
\hline Santa Ines & SIN & -3.6 & 45.4 & 0.1 & 25036 & -9066 & 92 \\
\hline Rondon do Para & RON & -4.8 & 48.2 & 0.6 & 24962 & -8539 & 539 \\
\hline Cocalinho & $\mathrm{COC}$ & -3.2 & 45.7 & 0.6 & 25172 & -9054 & 583 \\
\hline Itinga & ITI & -4.3 & 47.0 & 0.7 & 24982 & -8781 & 345 \\
\hline Gurupizinha & GUR & -3.7 & 47.5 & 1.2 & 25186 & -8747 & 1098 \\
\hline Santa Teresa & STE & -2.5 & 45.8 & 1.3 & 25366 & -9087 & 1227 \\
\hline Paragominas & PAR & -3.1 & 47.3 & 1.7 & 25324 & -8824 & 1501 \\
\hline Goianesia & GOI & -3.7 & 49.1 & 2.1 & 25326 & -8465 & 1900 \\
\hline Bela Vista & BLV & -1.8 & 46.2 & 2.2 & 25574 & -9075 & 2040 \\
\hline Tailandia & TAI & -3.2 & 49.0 & 2.5 & 25438 & -8522 & 2276 \\
\hline Tome Acu & TOM & -2.4 & 48.1 & 2.7 & 25559 & -8740 & 2510 \\
\hline Braganca & BRA & -1.1 & 46.8 & 3.1 & 25782 & -9028 & 2969 \\
\hline Tatuoca & TTB & +1.2 & 48.5 & 4.0 & 25866 & -8747 & 3771 \\
\hline
\end{tabular}

to an overhead current $C$ at the height $h^{1}$ and whose vertical component is that of a current $-C$ at the same height vertically above the actual overhead current. Thus the induced field has components

$H^{1}=\frac{2 C h^{1}}{x^{2}+h^{1^{2}}}$

$Z^{1}=\frac{2 C x^{1}}{x^{2}+h^{1^{2}}}$

Forbush and Casaverde (1961) separated the latitudinal profiles of $\Delta H$ and $\Delta Z$ at $75^{\circ} \mathrm{W}$ chain of stations operating during 1957-1959 into the external part due to currents in the ionosphere and at the internal part due to induced currents. Figure $2 \mathrm{~d}$ shows the latitudinal variations of the total, external and internal parts of $\Delta H$ and $\Delta Z$ adopted from Forbush and Casaverde. It is to be noted that the induced currents generally create a magnetic field at the Earth's surface whose horizontal component is in the same direction as the horizontal component due to the external sources whereas the vertical component by the induced current is opposite to the vertical component produced by the external sources. This means that the induction increases the horizontal component and decreases the vertical component.

It was shown that the external and internal parts of the range $H$ were respectively 0.71 and 0.29 times the observed total range $H$. Thus the ratio of internal to external current was about 0.40 . Similar analyses of the data from the chain of station in Ethiopia (around $40^{\circ} \mathrm{E}$ longitude) for the period November 1970 to May 1971 were made by Carlo et al. (1982). The average induced effect as measured from the ratio of internal to external component $(\Delta H i / \Delta H e)$ for $\mathrm{Sq}$ variations was found to be 0.38. Rigoti et al. (1999) estimated that the internal part of $\Delta H$ observed in Eastern Brazil region was less than $10 \%$ of the external component. These differences may be due to the presence of large conducting region in eastern part of Ethiopia.

\subsection{Later developments of EEJ models}

Sugiura and Cain (1966) presented a modified version of Chapman's thin shell model associated with a model atmosphere and found that the calculated longitudinal variation of the EEJ was in fair agreement with the observations. Untiedt 
(1967) proposed a numerical 2-D model that allows the vertical currents and consequently a meridian current system. This assumption increased the width of EEJ and improved considerably the fit to the observations. Sugiura and Poros (1969) improved Untiedt's model by using a spherical harmonic representation of the Earth's magnetic field, instead of a simple dipole magnetic field. Models using a twodimensional distribution of ionospheric currents have been proposed by Onwumechilli (1967), Agarwal and Weaver (1990) and others but the structure of the equatorial electrojet current remained fundamentally the same as in Chapman's model.

\section{Equatorial electrojet modeling, Brazilian region}

The main aim of the Brazilian experiment was to derive the spatial characteristics of the EEJ and to determine the Earth's conductivity structures by means of the geomagnetic induction process. Rigoti et al. (1999) have described the analysis of $\mathrm{H}$ and $\mathrm{Z}$ data on 16 selected quiet days. They were aware of the very large geomagnetic declination in the region $=20^{\circ} \mathrm{W}$ but no analysis of the declination $(D)$ or eastward magnetic field component $(Y)$ data has been described so far. The main parameters of EEJ determined were the positive current intensity $I=67000 \pm 20000 \mathrm{~A}$, and the half width $=$ $403 \pm 67 \mathrm{~km}$ and the centre was located at $21 \pm 16 \mathrm{~km}$ south of the dip equator.

The magnetic variation observed at the surface of the Earth comprises the primary fields generated by external (ionosphere, magnetosphere) currents plus secondary fields produced by internal currents induced in the Earth by the primary field variations. It was estimated that there was only a small $(<10 \%$ of the external) internal contribution attributed to the EEJ regular daily variation. The mean depth of EEJ image was estimated to be at the depth of $1010 \pm 134 \mathrm{~km}$.

\subsection{Geomagnetic induction anomalies in Eastern Brazil}

Rigoti (1994) has described his study of the deep geomagnetic sounding of the East Brazilian region and here we reproduce some important results which may affect the equatorial electrojet.

The examination of the magnetograms during the $\mathrm{SC}$ at 23:30 UT on 26 November 1990 showed similar traces in the $\mathrm{X}$ and $\mathrm{Y}$ components at the centre of the eletrojet (BAC) and the edges of EEJ (BRA and SJP). The short period oscillation in the $\mathrm{Z}$ component showed a reversal of sign at BAC. The stations BAC and SJP are at opposite sides of an anomaly associated with the deepest part of the Parnaiba Basin. For variations of 2 to $3 \mathrm{~h}$ period, the coastal station BRA showed most significant differences in $Z$ associated with large coast-effect. Contour maps of Fourier coefficients showed an anomaly in the $\mathrm{Y}$ amplitude in the southern part of the array and an anomaly in the northwestern region ex- tending towards the centre of the array, with a northwestsoutheast orientation . Induction arrows showed large amplitude at stations in the southeast, best exemplified by BAL. The orientation of the real arrows did not vary much with period for stations in central and western parts of the array(e.g. BAL, SNE). Whereas, stations in the eastern part (e.g. STE, $\mathrm{COC}$ ) did rotated as the period increased, pointing to the course in the larger period. Transfer functions under the influence of the electrojet showed remarkably similar features in the night and day at the period $11.6 \mathrm{~min}$. At the period 25.6 min some influence of EEJ was evident. At the period of $42 \mathrm{~min}$ EEJ was less dominant. At the period $6.8 \mathrm{~h}$ the maps of real $Z$ exhibited the behavior of the electrojet field only; only small distortions were observed in the northeastern corner and in the southern region. It was concluded that, when the amplitude of the EEJ is large, the distortions of the daily ranges caused by the local induction are not significant.

\section{Two sheets of currents in the E-region above the dip equator}

Combining the large set of ionospheric drift observations, ionospheric sounding results and geomagnetic data at stations close to the dip equator in India, Rastogi (1975) has shown that $\Delta H$ observed at electrojet stations are the resultant effect of two currents (1) one always flowing eastward at $106 \mathrm{~km}$ and associated with the global Sq current system due to the electric field system generated by the solar-lunar tides; (2) the second current at a lower level of $100 \mathrm{~km}$ flowing eastward during normal and westward during partial or full electrojet periods. Simultaneously two currents flowing at different directions at altitudes in the E-region of the ionosphere over the magnetic equator have been directly recorded by forward scatter VHF Doppler radar (Carter et al., 1976). The Sq and EEJ currents can be separated by suitable model calculations if a reasonable latitudinal network of geomagnetic stations is available. To a good approximation EEJ can be estimated by subtracting $\Delta H$ at a low latitude station just outside the EEJ belt from total observed $\Delta H$ at the station close to the centre of the EEJ belt in the same longitude sector. These pairs of stations have been shown to be Huancayo, Fuquene for American and Trivandrum, Alibag for Indian longitudes (Rastogi et al., 1977). Fambitakoye and Mayaud (1976) have made their analyses separating the observed daily variations of the magnetic $\mathrm{H}$ and $\mathrm{Z}$ fields into components: one corresponding to the electrojet current flowing within a narrow band along the dip equator and the remainder due to the component of a planetary current system.

In this paper, we describe the analysis of geographic northward $\mathrm{X}$, geographic eastward $Y$ and vertical downward $\mathrm{Z}$ components at the 26 stations presented in the Sector 1.The data are averaged over 16 quiet days. The direction of the 


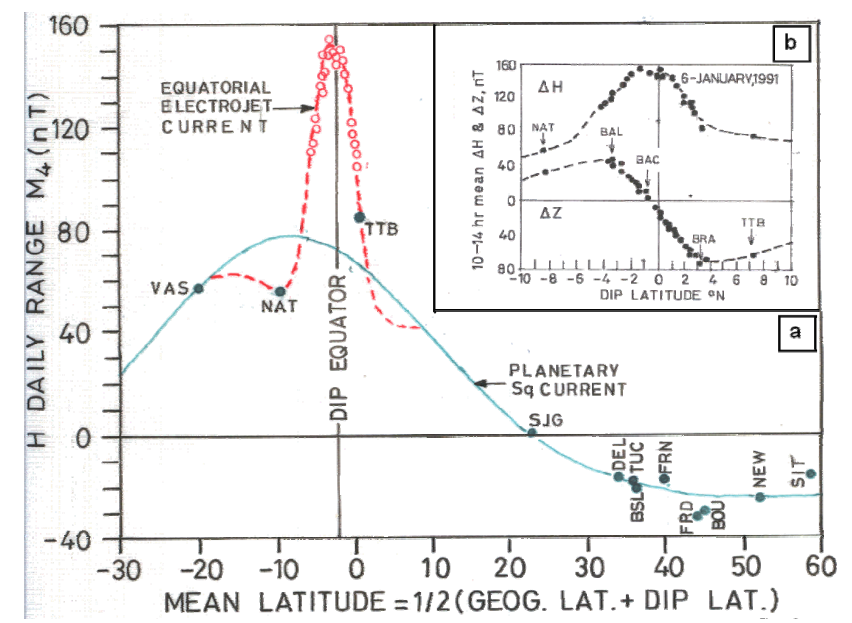

Fig. 3. Latitudinal variations of the four hourly (10-13) mean daily range $\mathrm{M} 4$ of $\mathrm{H}$ due to planetary and electrojet currents for 6 January 1991 (after Rigoti et al., 1999).

total horizontal field $H$ with respect to the geographic meridian was calculated according to the equation;

Direction of $H$ east of geographic north $=\theta=\arctan (\Delta Y / \Delta X)$

The data from Acailandia, Imperatriz and Vila Macdo Rio have not been included in the analysis.

\section{Results of the analysis}

Figure 3 is drawn after Fig. 5 of Rigoti et al. (1999). The diagram also shows the EEJ and $\mathrm{Sq}$ variations as obtained by Rigoti et al. (1999) from the modeling based on all available data for the longitude zone. It is to be noted that there was not a single station between the magnetic equator and the northern Sq focus which was close to the station San Juan, SJG, (geog. lat. $=18.1^{\circ}$, geog. long. $\left.=293.9^{\circ}\right)$. The Sq variation was thus based on the data from high latitude stations outside the low latitudes current system. Thus, it seems improper to separate the EEJ component at the network of stations by subtracting so calculated Sq current contributions of $\Delta H$ from the observed $\Delta H$ at equatorial latitudes.

It is interesting to note that the ranges $\mathrm{M} 4$ of $H$ at equatorial stations are fairly symmetrically distributed with respect to the dip equator. In the inset figure, the EEJ portion of the latitudinal profile of range M4 of $\Delta H$ and $\Delta Y$ are shown in expanded version for the typical quiet day, 6 January 1991. Range $\Delta H$ was maximum at BAC close to the dip equator, more precisely about one degree south of it. The profiles of range $\Delta Z$ showed zero crossing at about $1^{\circ}$ dip latitude, maximum positive value at close to the latitude at BAL and minimum value close to the latitude of BRA. Both the stations NAT and TTB were outside the EEJ belt. The declination data at these off-EEJ stations were not available and

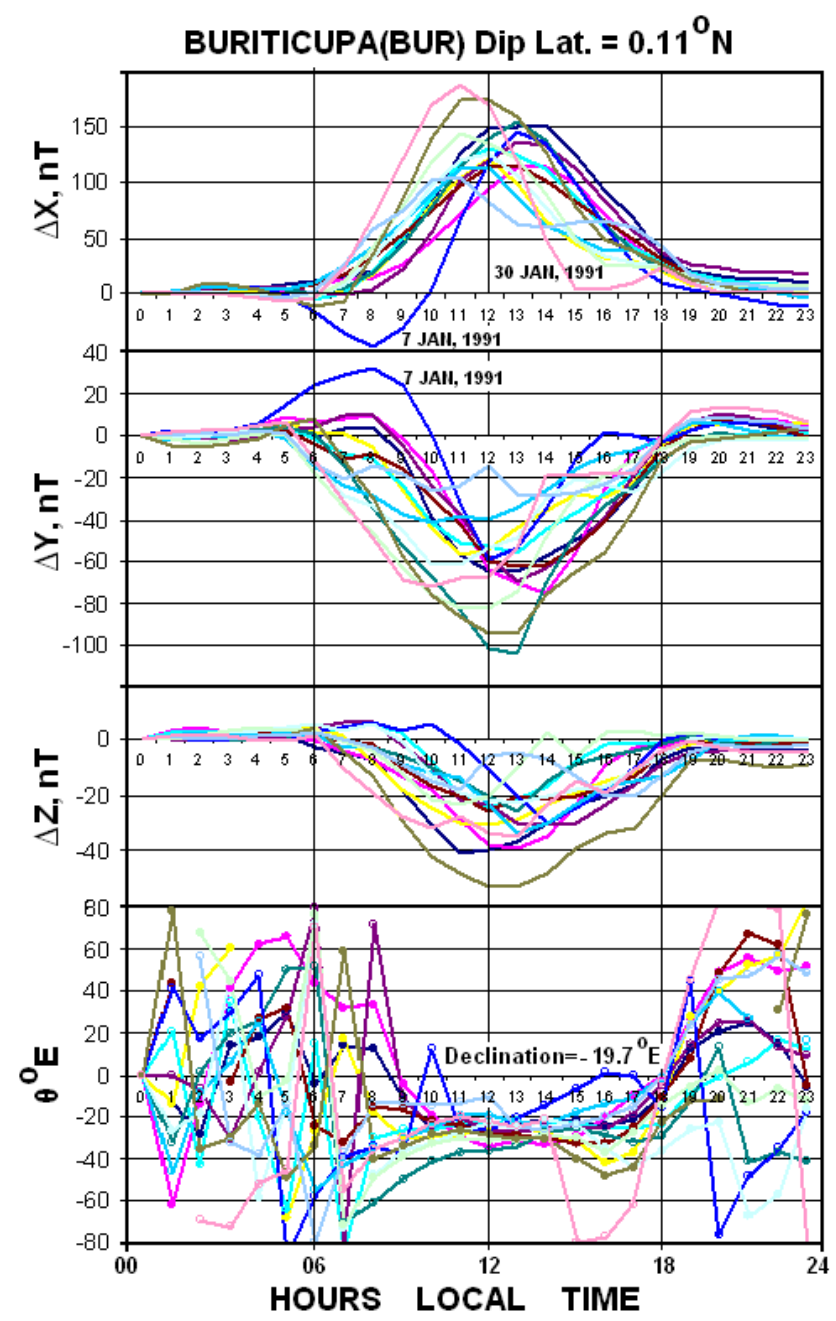

Fig. 4a. Overlapping plots of the daily variation of $\Delta X, \Delta Y, \Delta Z$ and $\theta$ direction of $H$ east of geographic north $=\arctan (\Delta \mathrm{DY} / \Delta \mathrm{DX})$ on all days for BUR.

no discussion of magnetic field variations at these stations is made here.

Rigoti et al. (1999) have presented the stacked curves of the daily variations of the hourly mean values of $\Delta H$ and $\Delta Z$ at all stations on a quiet day 6 January 1991. $\Delta H$ showed a single maximum at about noon at all of the stations with largest range $\Delta H$ at the BAC, ARA, BUR and SIN stations close to the equator. The noon values of $\Delta Z$ were close to zero at ARA, increased southward to reach a maximum (downward field) near SSP and a minimum (upward field) near BRA.

To illustrate the coherence or the variability of the field, in Fig. 4 are shown the overlapping daily variation curves for $\Delta X, \Delta Y, \Delta Z$ and $\theta$ at the station BUR for all of the days under study. The $\Delta X$ curves seem to be consistent with a midday maximum, except a case of early morning counter electrojet (CEJ) event on 7 January 1991 and an evening CEJ 

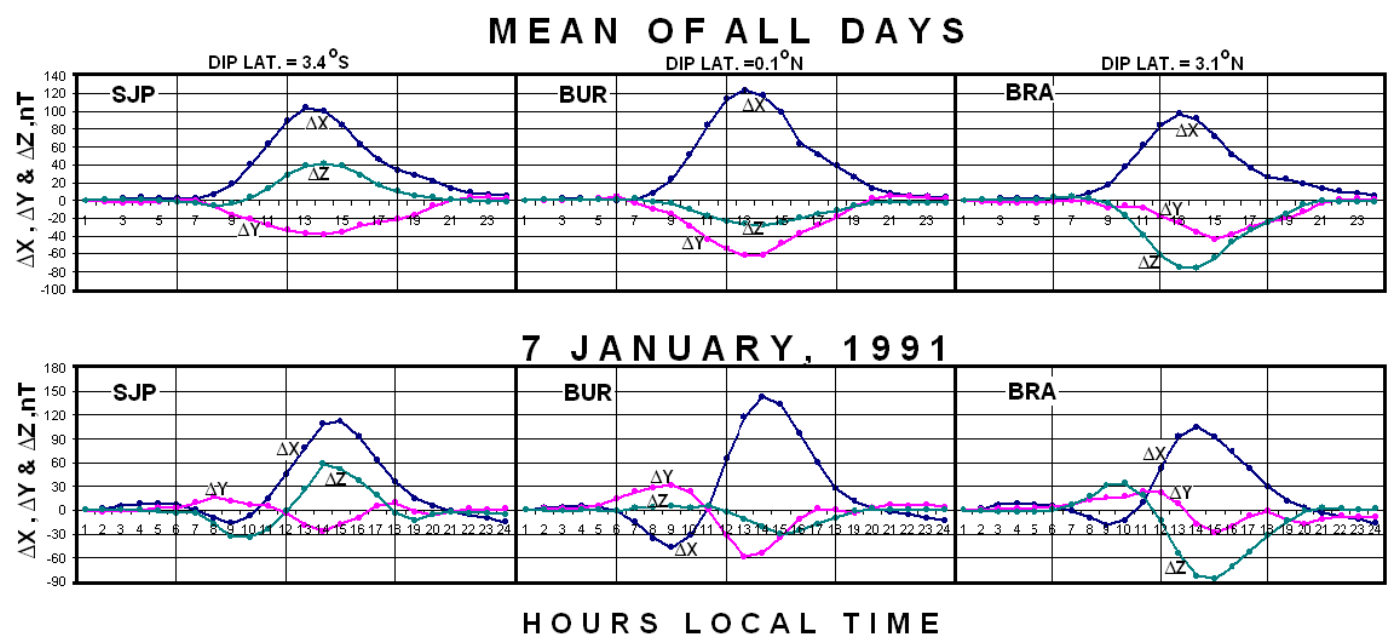

Fig. 4b. Daily variations of $\Delta X, \Delta Y$ and $\Delta Z$ at southern fringe station SJP, equatorial station BUR and northern fringe station BRA, averaged over all days and on an individual day 7 January 1991.

event on 30 January 1991, when $\Delta \mathrm{X}$ reached a level below the night time base value. The $\mathrm{Y}$ curves showed consistently a midday minimum; a morning maximum a on 7 January 1991 associated with CEJ event is clearly seen. The $\mathrm{Z}$ curves show comparatively larger scatter from one day to another characteristic of an equatorial station. The values of $\theta$ are extremely random for the night time hours and fairly consistent during the midday hours. The variability of night time values is due to almost zero values of individual $\Delta X$ and $\Delta Y$, $\theta$ being equal to $\operatorname{arc} \tan \Delta Y / \Delta X$.

In Fig. $4 \mathrm{~b}$ are shown the mean daily variations of $\Delta X$, $\Delta Y$ and $\Delta Z$ and on the single abnormal day, 7 January 1991 at stations SJP, BUR and BRA. At the southern station SJP, large midday maxima of $\Delta X$ and $\Delta Z$ and a flat minimum of $\Delta Y$ are clearly seen. At the equatorial station BUR a large midday maximum of $\Delta X$ and a midday minimum of $\Delta Y$ are observed. At northern station, BRA, both $\Delta Z$ and $\Delta Y$ show a midday minimum while $\Delta X$ has a maximum at noon.

On the abnormal day, 7 January 1991, a depression of $\Delta X$ is seen at all stations around the sunrise period indicating a counter electrojet event. During the same period $\Delta Z$ shows a minimum at SJP and a maximum at northern station BRA; expected of a westward electrojet current. At the electrojet station BUR, the depression of $\Delta X$ was associated with a maximum of $\Delta Y$ suggesting that both $\Delta X$ and $\Delta Y$ are intimately connected with each other.

The 26 stations were divided into 6 groups according to the geographic latitude $0^{\circ}$ and $1^{\circ}, 1^{\circ}$ and $2^{\circ}, 2^{\circ}$ and $3^{\circ}, 0^{\circ}$ and $-1^{\circ},-1^{\circ}$ and $-2^{\circ}$ and last one for less than $-2^{\circ}$. Daily variations of $\Delta X, \Delta Y$ and $\Delta Z$ and $\theta^{\circ} \mathrm{E}=\tan ^{-1} \Delta Y / \Delta X$ for each group of stations are shown in Fig. 5a. The individual stations included in each of the groups are also indicated in the plots for $\Delta X$ in the top of the figure. As expected, the daily variation of $\Delta X$ for all groups showed a peak around noon. The profile of $\Delta Z$ showed a maximum at southern and a minimum at northern stations. These features are as expected of the EEJ models discussed earlier. The peak $\Delta Z$ is larger at the northern than at the corresponding southern station which is an abnormal feature for this region. The daily variations of the eastward $(\Delta Y)$ showed a minimum around noon, just opposite to the corresponding variations of $\Delta X$. The maximum deviation of $\Delta Y$ was at stations close to the dip equator.

In Fig. $5 \mathrm{~b}$ are shown the hourly values of $\Delta X$ versus $\Delta Y$ loops for each of the station groups. At stations close to mean dip latitude $0.6^{\circ} \mathrm{S}$ and $0.3^{\circ} \mathrm{N}$ the loop are inclined respectively to $25^{\circ}$ and $21^{\circ}$ west of north compared to the mean declination of $20^{\circ}$ west of north. The direction of the current was $20^{\circ}$ west of north for station with dip latitude $3.0^{\circ} \mathrm{S}$; it was $16^{\circ}$ west of north for station with dip latitude $1.7^{\circ} \mathrm{S}$ and was $23^{\circ}$ west of north for station with dip latitude $1.4^{\circ} \mathrm{N}$. At all these stations the loops were fairly narrow suggesting that the direction of the ionospheric current was fairly constant throughout the daytime hours. The loops for the northernmost stations (dip latitude $2.3^{\circ} \mathrm{N}$ ) were comparatively broader. The direction $\theta$ was $10^{\circ}$ west during the prenoon hours but increased to more than $30^{\circ}$ west during the evening hours. This suggested the effect of a mid-latitude Sq current system over the EEJ current system at the northern edge of the equatorial electrojet belt. Rastogi (2006) showed that both the $\mathrm{Sq}(\mathrm{H})$ and $\mathrm{sfe}(\mathrm{H})$ vectors at the equatorial stations Addis-Ababa and M'Bour aligned precisely along the magnetic meridian in the particular region.

In Fig. 6 are shown the variations of M4 (mean of 1000 to $1300 \mathrm{~h}$ ) values of $\Delta X, \Delta Y, \Delta Z$ and $\theta$ averaged over all the 16 quiet days with respect to dip latitude. The variation of $\Delta \mathrm{X}$ showed a maximum between 0 and $-1^{\circ}$ dip and it decreases at southward as well as at northward stations. The variation of $\Delta Z$ showed a maximum at latitudes close to that of BAL (dip lat. $2.9^{\circ} \mathrm{S}$ ) and a minimum at latitude close to 
that of BRA, (dip lat. $3.1^{\circ} \mathrm{N}$ ) crossing the zero values at $1^{\circ} \mathrm{S}$ dip latitude close to the stations SAL and BAC. The profile of $\Delta Y$ showed a broad minimum between $0^{\circ}$ and $1^{\circ} \mathrm{S}$ and slowly increases towards the edge of the EEJ belt. It is interesting to note that the minimum value of $\Delta Y$ was $-60 \mathrm{nT}$ compared to the corresponding value of $135 \mathrm{nT}$ for $\Delta X$. The value of the direction of $\mathrm{H}$ vector showed a flat maximum of $25^{\circ}$ west of north at stations close to the equator and with a suggestion of decreasing $\theta$ at latitudes 2.5 south of the equator.

To test if the latitudinal variations of $\mathrm{X}, \mathrm{Y}$ and $\mathrm{Z}$ were dependent on the strength of the equatorial electrojet current, two days were chosen, 29 June 1991 and 30 January 1991 when extreme value of $\Delta X$ o was recorded. The value of the daily range of $\Delta X$ at BUR was the smallest $(=120 \mathrm{nT})$ on 29 January 1991 and largest $(=226 \mathrm{nT})$ on 30 January 1991, an increase by a factor of about 1.9. The daily variations $\Delta X$, $\Delta Y$ and $\Delta Z$ on 29 and 30 January 1991 are shown in Fig. 7. It is important to note that the latitudinal variations of $\Delta Z$ showed zero crossing at the latitude of $1.0^{\circ} \mathrm{S}$ on the weak as well as strong current day. The minimum daily range of $\Delta Z$ was $-44 \mathrm{nT}$ on 29 January and $-98 \mathrm{nT}$ on 30 January showing an increase by a factor of about 2.2. The maximum value of daily range $\Delta Z$ was $40 \mathrm{nT}$ on 29 January and $76 \mathrm{nT}$ on 30 January showing an increase by a factor of $76 / 40=1.90$. The largest daily ranges of $Y$ were $-28 \mathrm{nT}$ on 29 January and $-78 \mathrm{nT}$ on 30 January, showing an increase by a factor of 2.79. With the present data it is not possible to identify any change in the width of the electrojet belt with the strength of the current at the centre of the belt.

Both the daily and latitudinal variations can be combined in contours of $\Delta X, \Delta Y$ and $\Delta Z$ on the grid of dip latitude versus the local time as shown in Fig. 8. The contours of $\Delta X$ show a high of $>140 \mathrm{nT}$ centered at 12:30 LT and slightly south of the dip equator. A minor low centered over dip equator between $+2^{\circ}$ and $-2^{\circ}$ dip latitude is also evidenced at pre-sunrise hours. The contours of $\Delta Y$ show a low $<60 \mathrm{nT}$ at noon over the dip equator. A minor maximum of $\Delta Y$ is also evidenced at pre-sunrise hours corresponding to the early morning counter electrojet. The contours of $\Delta Z$ show a high $>+30 \mathrm{nT}$ at noon around $2.5^{\circ} \mathrm{S}$ dip latitude and low $<-70 \mathrm{nT}$ at noon around $2.5^{\circ} \mathrm{N}$ dip latitude. The $0 \mathrm{nT}$ contour is significantly shifted to $1^{\circ} \mathrm{S}$ dip latitude. Thus the EEJ width seems to be larger in north than in south of the equator. A counter electrojet is evidenced by a high $Z$ at $2^{\circ} \mathrm{N}$ and a low $Z$ at $2^{\circ} \mathrm{S}$ dip latitude around sunrise hours.

From the present analysis, the average centre of the electrojet ribbon has been estimated at about $1^{\circ} \mathrm{S}$ dip latitude at ground level, as computed by the from International Geomagnetic Reference Field (IGRF) program in Space Physics Interactive Data Resources (SPIDR) website (http://spidr. ngdc.noaa.gov/spidr/index.jsp). In Fig. 9 are given the variations, with the geographic latitude, of the inclination at the ground level and at $100 \mathrm{~km}$ altitude in the ionosphere for $46^{\circ} \mathrm{W}$ geographic longitude. The inclination of the field

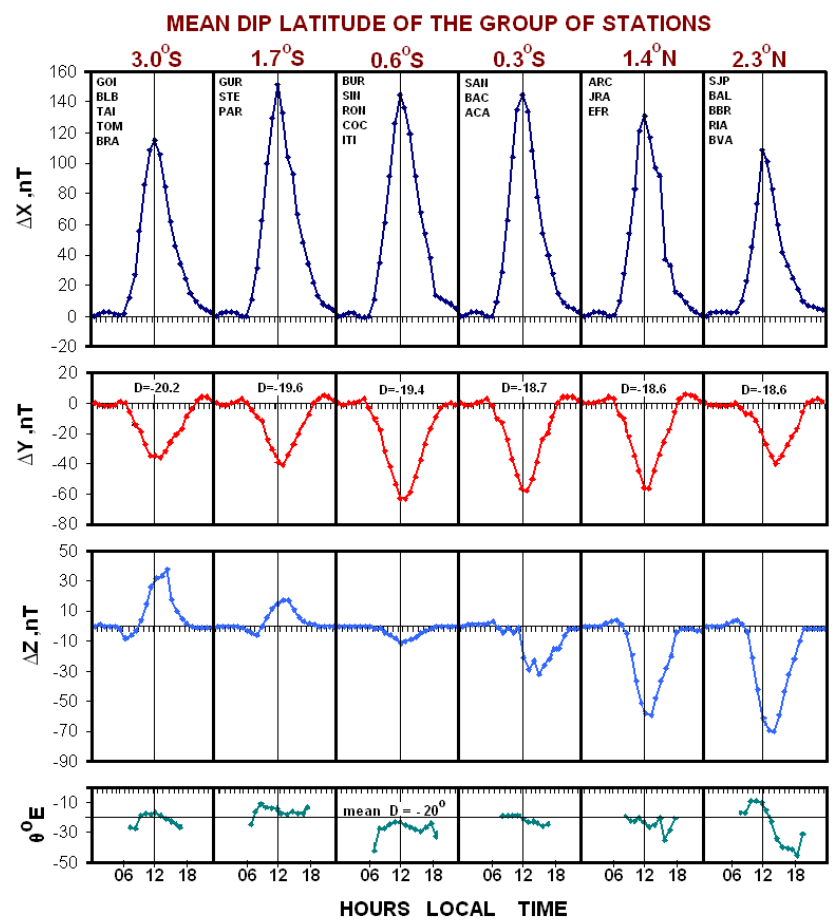

Fig. 5a. Mean daily variations of ranges of $\mathrm{X}, \mathrm{Y}$ and $\mathrm{Z}$ fields and of the electrojet current direction, $\theta$ (direction of $\mathrm{H}$ east of geographic north $=\operatorname{arc} \tan (\Delta Y / \Delta X)$ averaged for groups of stations at $3^{\circ} \mathrm{S}$, $2^{\circ}-1^{\circ} \mathrm{S}, 1^{\circ}-0^{\circ} \mathrm{S}, 0^{\circ}-1^{\circ} \mathrm{N}, 1^{\circ}-2^{\circ} \mathrm{N}$ and $2^{\circ}-3^{\circ} \mathrm{N}$ dip latitudes for all the sixteen quiet days.

lines is zero at $3.54^{\circ} \mathrm{S}$ geog. latitude at the ground level and at $3.72^{\circ} \mathrm{S}$ geog. latitude at the ionospheric level. Thus, if one considers the centre of EEJ relevant to the ionospheric level then it is shifted southward by only about $0.18^{\circ}$.

\subsection{Day-to-day variation of $\Delta X, \Delta Y, \Delta Z$ and $\theta$}

Figure 10 shows the day-to-day variations of M4 ranges of $\Delta X, \Delta Y, \Delta Z$ and $\theta$ on all available days for the equatorial station BAC and for the stations, BAL and BRA near the edge of EEJ. The range $\Delta X$ is seen to vary appreciably from one day to another, especially at the equatorial station $\mathrm{BAC}$, the extreme values were 110 and $162 \mathrm{nT}$. The range $\Delta Y$ seems to vary comparatively by larger amount and synchronously at all stations. In a seemingly quietest day, 6 January 1991, the ranges of $\Delta Y$ were around $-50 \mathrm{nT}$ at the edge of EEJ and about $-100 \mathrm{nT}$ near the centre of EEJ. The variations of the $\Delta X$ range were comparatively lower than that of $\Delta Y$. Ranges of $\theta$, the direction of $H$ vector varied over large amount from $-35^{\circ}$ to $+8^{\circ}$ East and seems to be synchronous at all stations.

Next, attempts are made to estimate any linear relationship between the different components of the magnetic field at the three stations.

Figure 11a shows the variation of $\Delta X(\mathrm{M} 4)$ at BRA and BAL with respect to that at $\Delta X(\mathrm{M} 4)$ at BAC. It has to be 


\section{MEAN DIP LATITUDE}

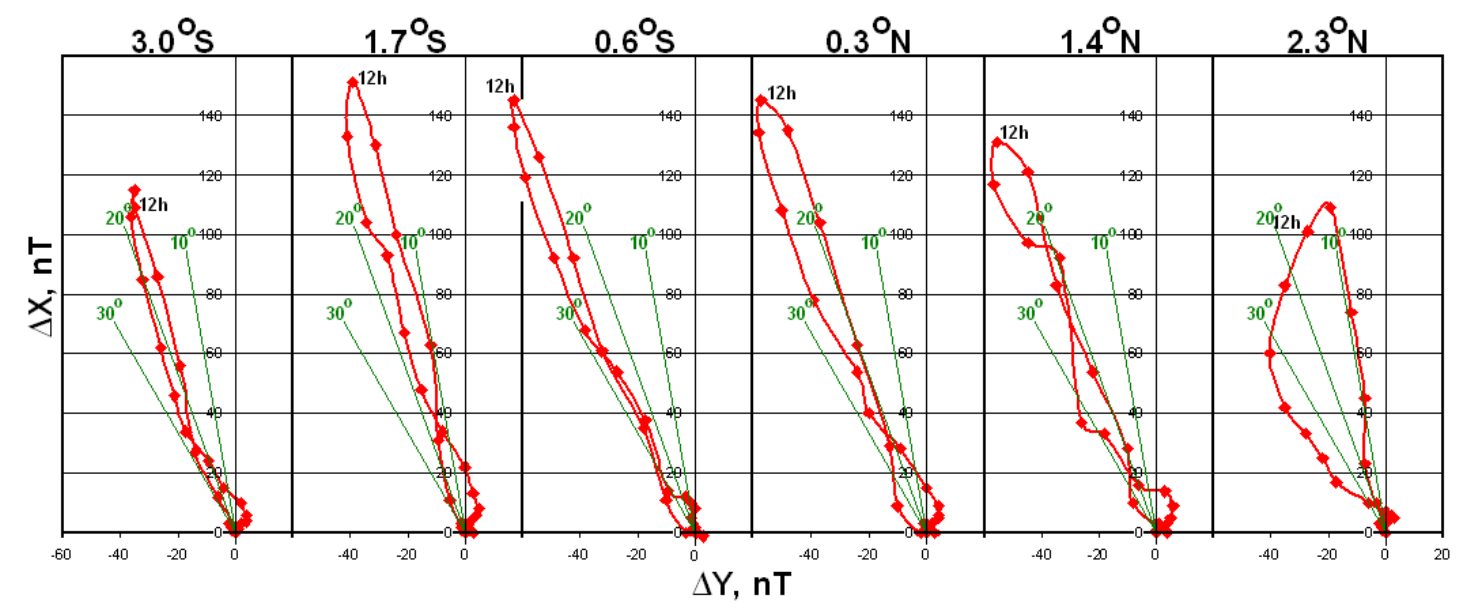

Fig. 5b. Plots showing the $\Delta X$ versus $\Delta Y$ loop of the Sq variations at each of the selected group of stations.

noted that we have rather poor sample of 14 data points only. The correlation coefficient for BAL and BRA with BAC are 0.49 and 0.39 , respectively. It is interesting to note that the slope of the regression line for $\triangle X \mathrm{BAC}$ versus $\triangle X \mathrm{BRA}$ is 0.24 and for $\Delta X$ BAC versus $\Delta X$ BAL is 0.35 . This suggests that with increasing latitude the range $\Delta X$ decreases faster in the north than in the south.

Figure $11 \mathrm{~b}$ shows the relationship of $\triangle Y(\mathrm{M} 4)$ with respect to $\Delta X(\mathrm{M} 4)$ for different stations BAL, BAC and BRA. The correlation coefficient is the almost the same for any pair of station being around -0.50 .

Figure $11 \mathrm{c}$ shows the relationships between range $\triangle Z(\mathrm{M} 4)$ with range $\Delta X(\mathrm{M} 4)$ for stations BAL, BAC and BRA. At the station BAC close to the dip equator there is no relationship between $\Delta Z$ with $\Delta X$. The southern station, BAL, $\Delta Z$ increases with increasing $\Delta X$, the slops being 0.30. At northern station, BRA, $\Delta Z$ decrease relatively faster with increasing $\Delta X$, the slope being 0.67 .

\subsection{Latitudinal variations of $\Delta X, \Delta Y$ and $\Delta Z$ for dif- ferent local hours}

In order to understand the latitudinal variations of the components of the magnetic field at different hours, the hourly means of $\Delta X, \Delta Y$ and $\Delta Z$ are plotted against dip latitude in Fig. 12. At 05:30 h, $\Delta X$ showed a flat variation with latitude. But at $06: 30 \mathrm{~h}$ and $07: 30 \mathrm{~h}$ a minimum of $\Delta X$ was evident centered over the dip equator. Only at $03: 30 \mathrm{~h}$ a maximum of $\Delta X$ is observed signifying the development of an eastward electrojet current. This equatorial maximum developed with them, was strongest around noon and disappeared by the evening hours.

$\Delta Y$ showed a mild equatorial counter electrojet by positive values at $05: 30 \mathrm{~h}$ and $06: 30 \mathrm{~h}$, but after $01: 30 \mathrm{~h}$, the $\Delta Y$ values turned negative and this equatorial minimum devel- oped deeper with time, was most developed around noon and slowly disappeared by the evening. The behavior of $\Delta Y$ is very similar but opposite in phase to that of $\Delta X$ and clearly suggest that the daily variation of $\Delta Y$ within the electrojet belt is closely linked with the electrojet current.

The latitudinal variations of $\Delta Z$ at $05: 30 \mathrm{~h}$ and $06: 30 \mathrm{~h}$ showed mild positive values at north and negative values in south suggesting the current to be westward. After 07:30 h $\Delta Z$ values became positive around $3^{\circ} \mathrm{S}$ and a negative around $3^{\circ} \mathrm{N}$ and became stronger till midday hours suggesting the development of the eastward electrojet current, which decreased slowly in the afternoon hours.

Thus, the latitudinal profiles of $\Delta X$ and $\Delta Z$ were in full conformity with the expectations of Chapman's model of equatorial electrojet but the behaviour of $\Delta Y$ has been anomalous.

Similar curves were shown by Fambitakoye and Mayaud (1976) for the H, Z and D data at the chain of stations in the Central African sector operating in 1968-1970. Figure 13 is drawn after the Fig. 1 of their paper. The characteristics of the equatorial electrojet are clearly indicated in the profiles of $\Delta H$ and $\Delta Z$. But the profiles of $\Delta D$ showed a smooth variation with latitude with no special feature at latitudes close to the equator. The reason for absence any special feature of $\Delta Y$ near the dip equator may be partly due to the data being average over all the months of the year.

Doumbia et al. (2007) have described the latitudinal variations of $\Delta H, \Delta D$ and $\Delta Z$ at different local hours. They did not find any special features at the dip equator in the latitudinal variations of $D$ at any hours of the day. They simulated the magnetic variation by NCAR thermosphere-ionosphereelectrodynamics general circulation model. There were little agreement, between the observed features of magnetic variations at electrojet stations and the theoretical results. 

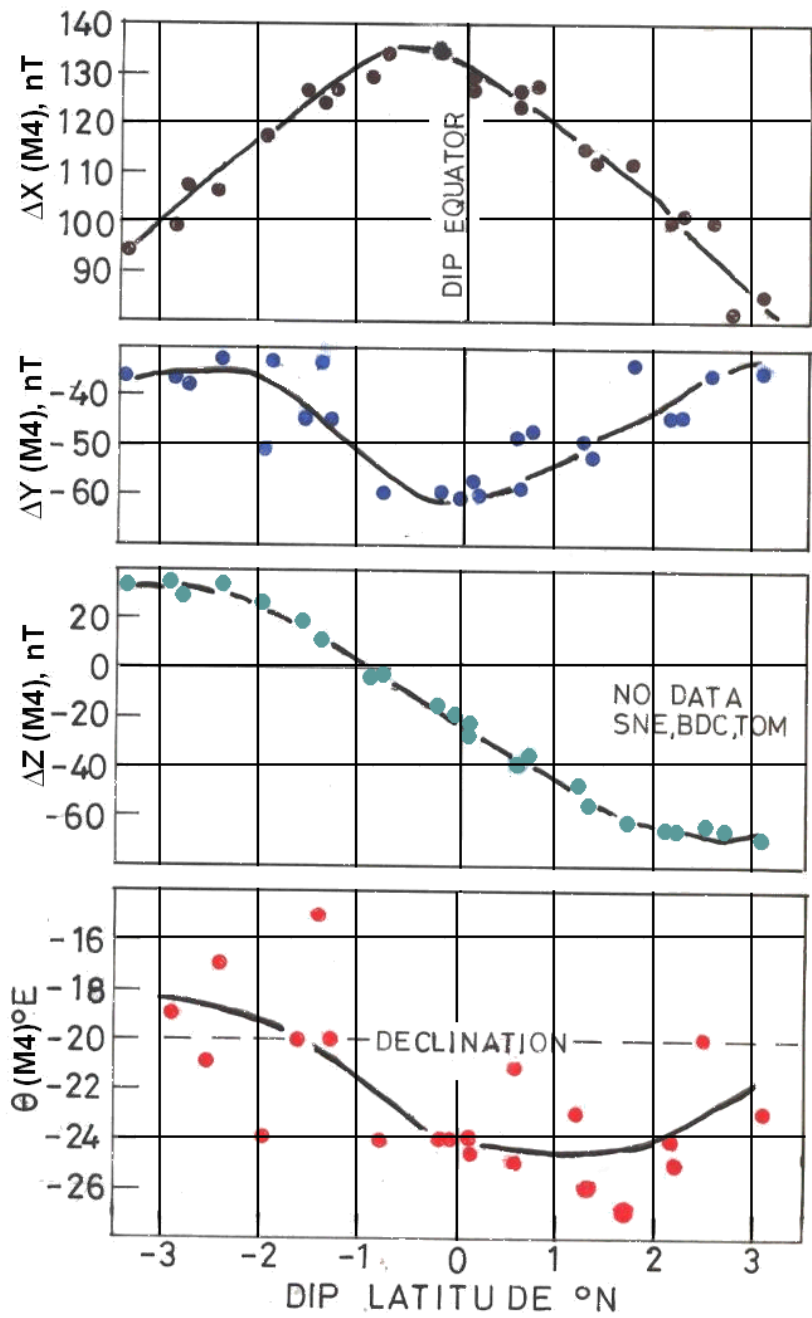

Fig. 6. Dip latitudinal variations of four hourly (10-13 h) mean daily ranges of $\Delta X(\mathrm{M} 4), \Delta Y(\mathrm{M} 4), \Delta Z(\mathrm{M} 4)$ and the electrojet current direction, $\theta(\mathrm{M} 4)$ averaged over all quiet days.

\section{Latitudinal asymmetry of Sq ranges of magnetic field components in the Peru region}

Forbush and Casaverde (1961) have described the features of magnetic field variations along the $75^{\circ} \mathrm{W}$ longitudes in Peru during the International Geophysical Year 1957-1959. Figure 14 here is redrawn after Fig. 12 in their publication. The latitudinal variation of the range of $H$ was symmetrical around geographic latitude of $13^{\circ} \mathrm{S}$, the location of the dip equator in that region. $\Delta Z$ showed strong latitudinal asymmetry with the magnitude of the positive peak south of the equator being about twice the magnitude of the negative peak the north of the dip equator. The cross over of the $\Delta Z$ curve was at a latitude north of the dip equator. The Declination showed a significantly larger daily range at southern magnetic latitudes than at northern latitudes.
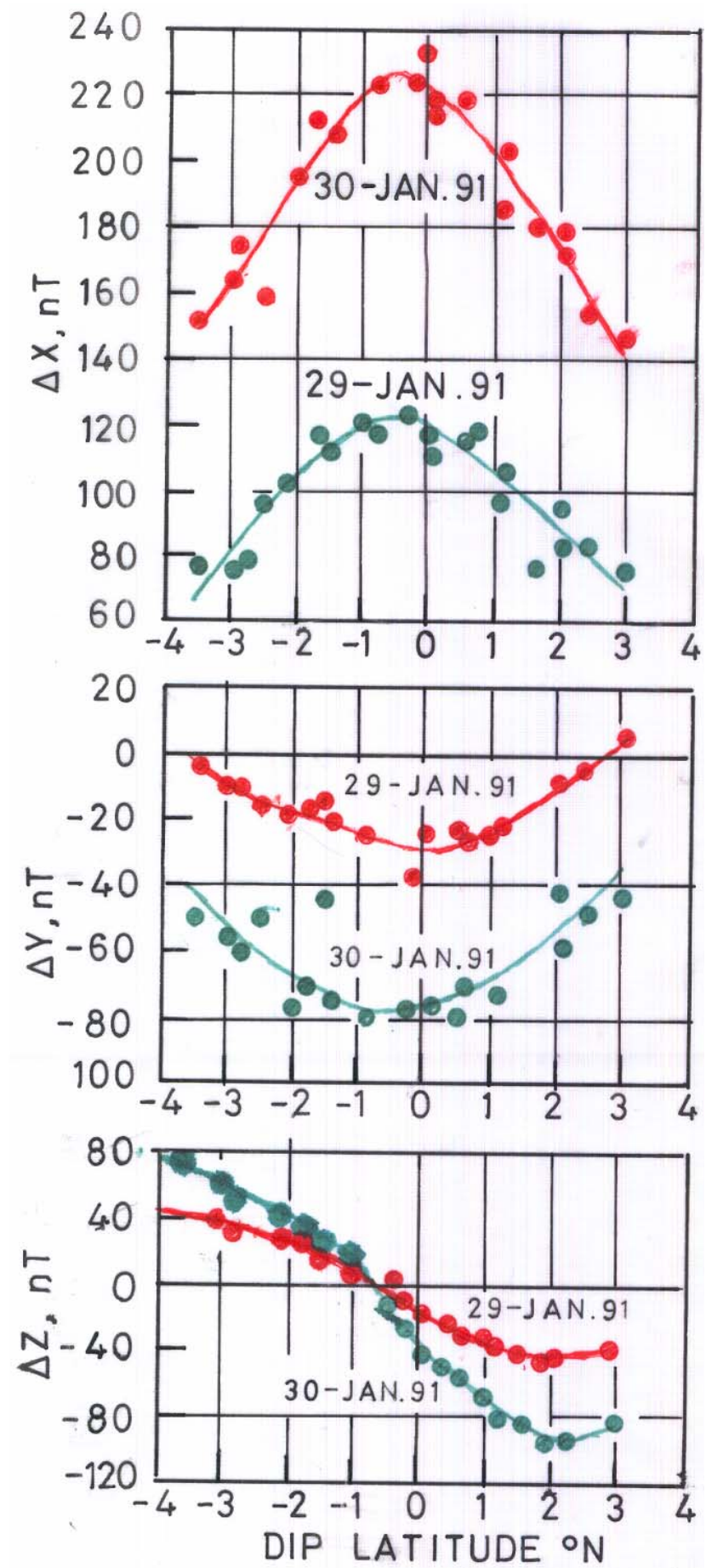

Fig. 7. Dip latitudinal variations of daily ranges of $X, Y$ and $Z$ on a strong (30 January 1991) and on a weak (29 January 1991) electrojet day.

The only other study of the geomagnetic data at a chain of stations on both sides of the dip equator was made by Fambitakoye and Mayaud but no information on any latitudinal asymmetry of the magnetic field components is mentioned. 


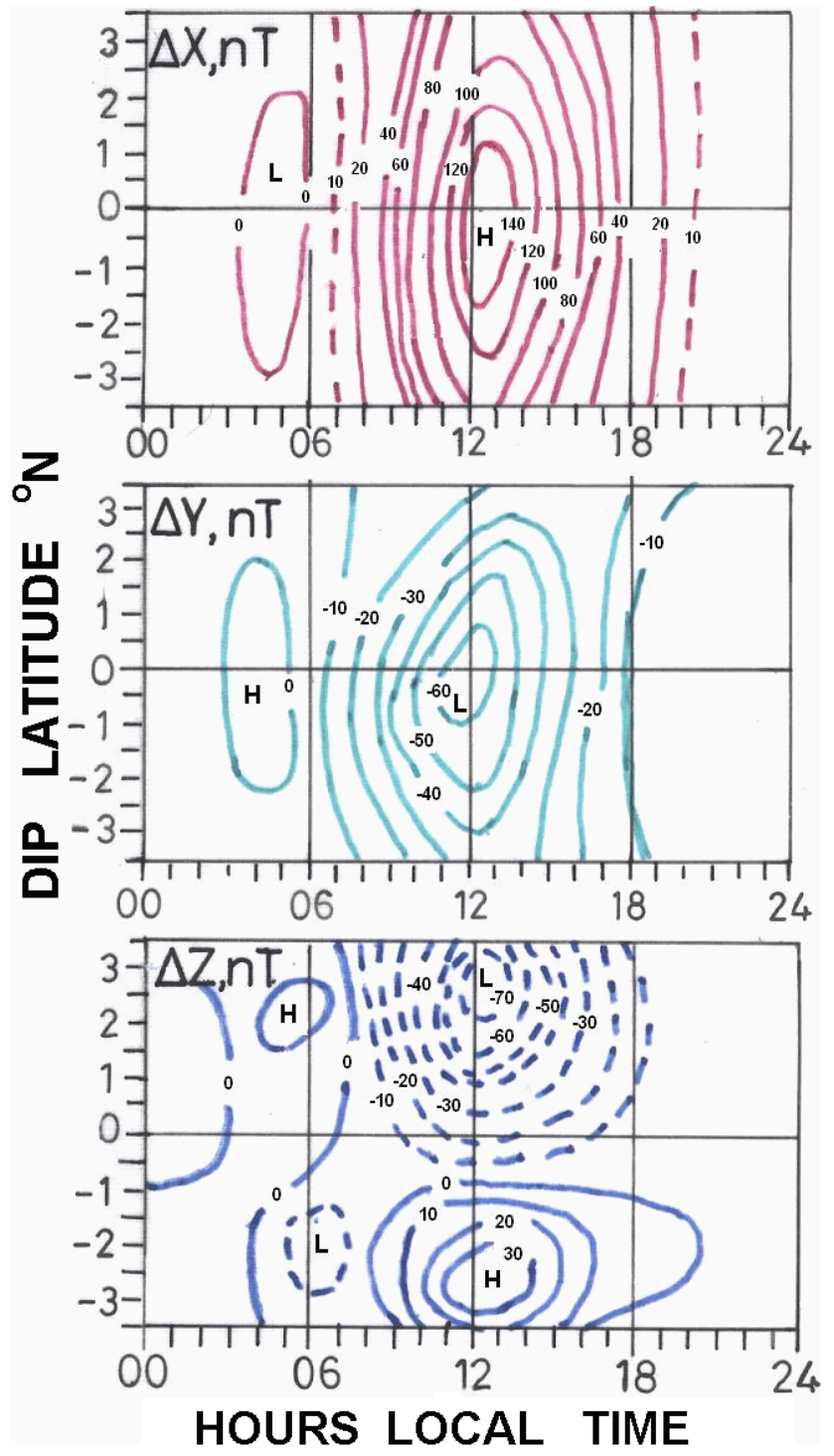

Fig. 8. Contours of the daily ranges $\Delta X, \Delta Y$ and $\Delta Z$ on the grid dip latitude versus local time averaged for all quiet days.

Similarly no such study is made of the data from the West African chain of stations operative during the International Equatorial Electrojet Year 1993-1994.

\section{Special features of the general magnetic field in the East Brazil sector}

Forbush and Casaverde (1961) had concluded that the equatorial electrojet in Peru near midday hours is centered over the dip equator. Fambitakoye and Mayaud (1976b) concluded that the "true" centre of the equatorial electrojet in Central African region $\left(30^{\circ} \mathrm{E}\right)$ at midday hours, coincided with the "effective" dip equator the position of which was predicted by the POGO 8/6 model. For the counter electrojet

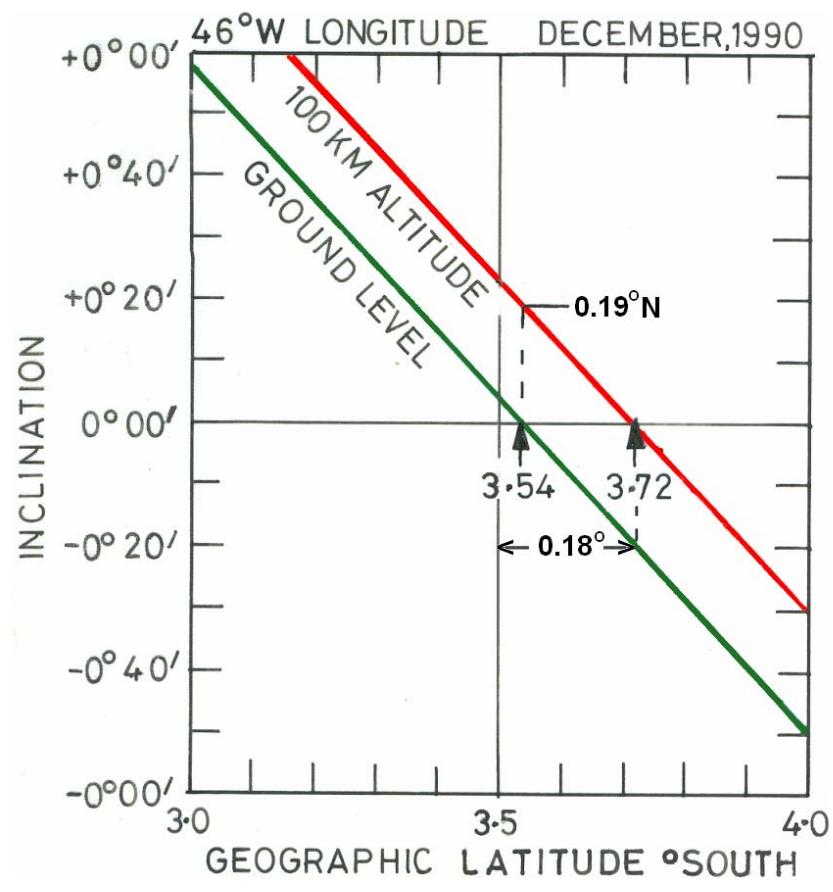

Fig. 9. Variation with geographic latitude of the inclination of field lines at the ground and ionospheric levels for $46^{\circ} \mathrm{W}$ geographic longitudes.

events in the morning and to a lesser extent in the afternoon hours, the centre location was systematically about $40 \mathrm{~km}$ north of the dip equator. As stated earlier, the EEJ centre in Brazil was located at $21 \pm 16 \mathrm{~km}$ south of the dip equator (Rigoti et al., 1999).

Jadhav et al. (2002) described analyses of scalar magnetic field data from the low orbiting Ørsted satellite from April 1999-March 2000 and concluded that the EEJ axis (centre of EEJ) closely followed the dip equator at an altitude of $106 \mathrm{~km}$ but there were small departures with the local time, with the minimum at noon. They also found that in the longitude regions near $39^{\circ} \mathrm{E}, 285^{\circ} \mathrm{E}$ and $315^{\circ} \mathrm{E}$ the angular deviation of EEJ axis from the dip equator was systematically larger than $0.5^{\circ}$.

Luhr et al. (2004) described their analyses of the local noon time magnetic data obtained by the low orbiting satellite CHAMP. Rather than interpreting the magnetic signatures, they determined the horizontal current distribution by using a general current model. Surprisingly they concluded that the electrojet current peaks right at the dip equator irrespective of season or longitude. They did not refer to earlier work of Jadhav et al. (2002) on the same topic. One has to examine why the analyses of satellite data by different scientists do not agree with each other and why the conclusions Luhr et al. (2004) are not in conformity with the ground magnetic field measurements.

Ivers et al. (2003) have discussed in detail the reasons for the equatorial electrojet profiles being different from the 

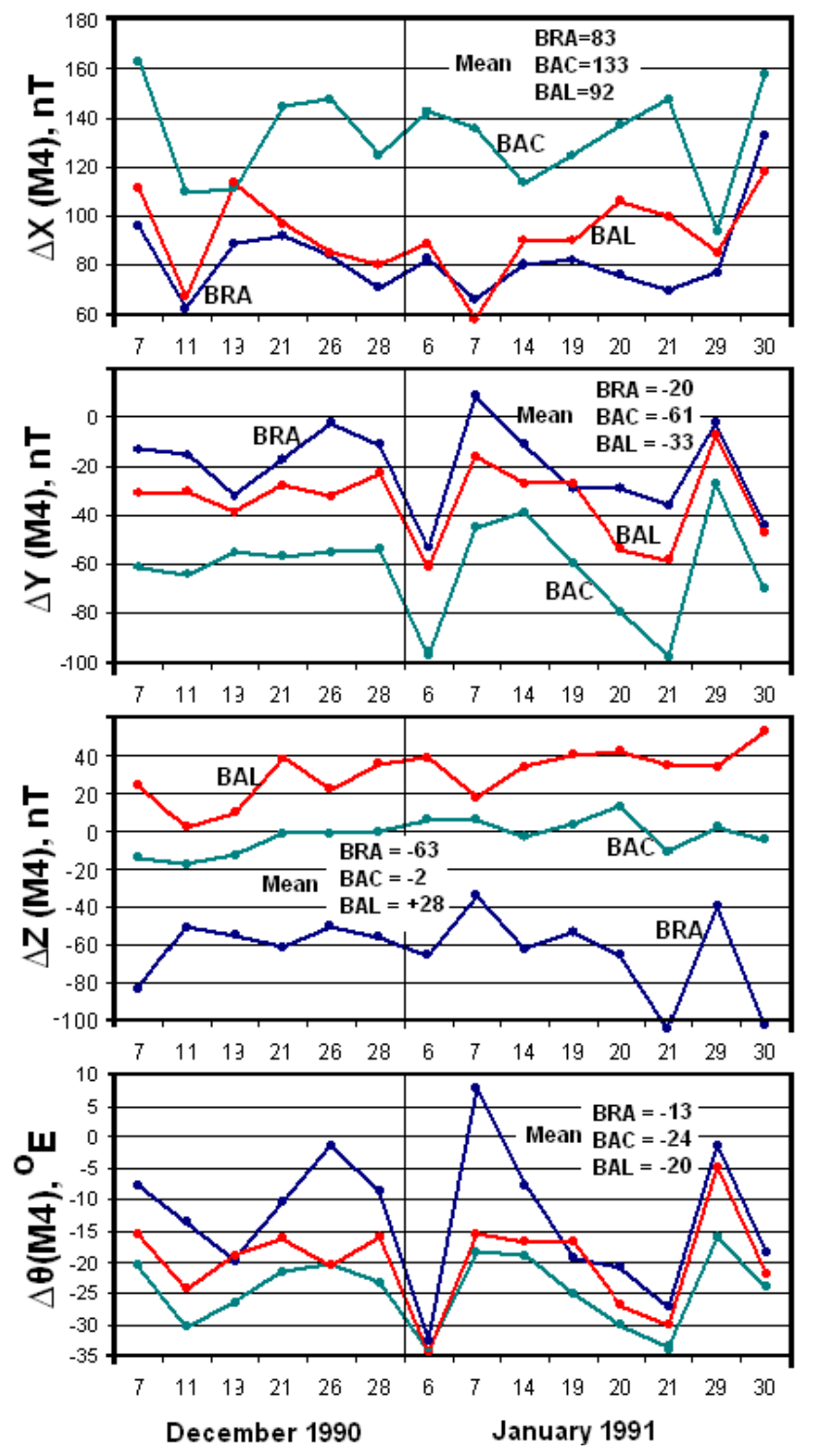

Fig. 10. Day-to-Day variations of $\Delta X, \Delta Y, \Delta Z$ and $\theta$ at the BAC station near the centre of EEJ and at the BRA and BAL stations near the edges of EEJ.

ground and satellite measurements. They suggested that the combination of long-track and spatial filtering of the satellite data modified the characteristics of the raw electrojet signature. The filtering does not overall degrade the amplitude of the electrojet, but produces artificial positive shoulders on either side of the negative trench.

Thus a comparison of the ground measurements of the electrojet morphology with the results from satellite measurements should be performed with caution.

Doumouya et al. (1998) have described the analysis of magnetic field $\mathrm{H}, \mathrm{D}$ and $\mathrm{Z}$ data at the chain of stations in West African longitudes during the IEEY period, 19931994. Figures 2 and 3 of their paper show a systematic

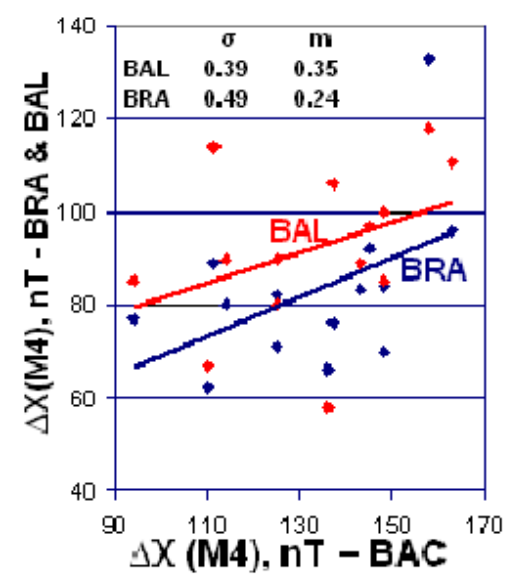

(a)

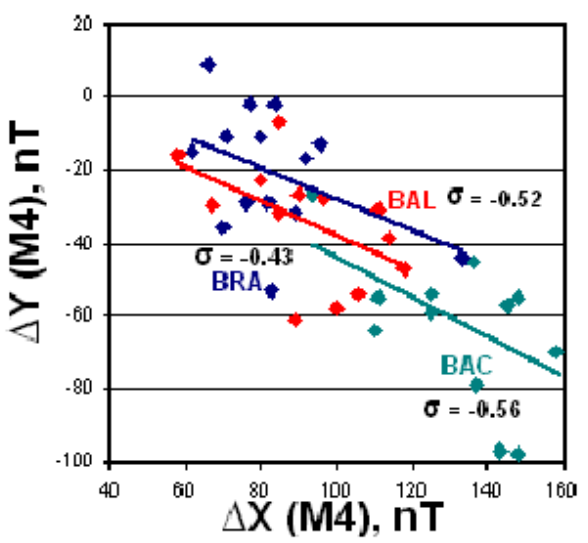

(b)

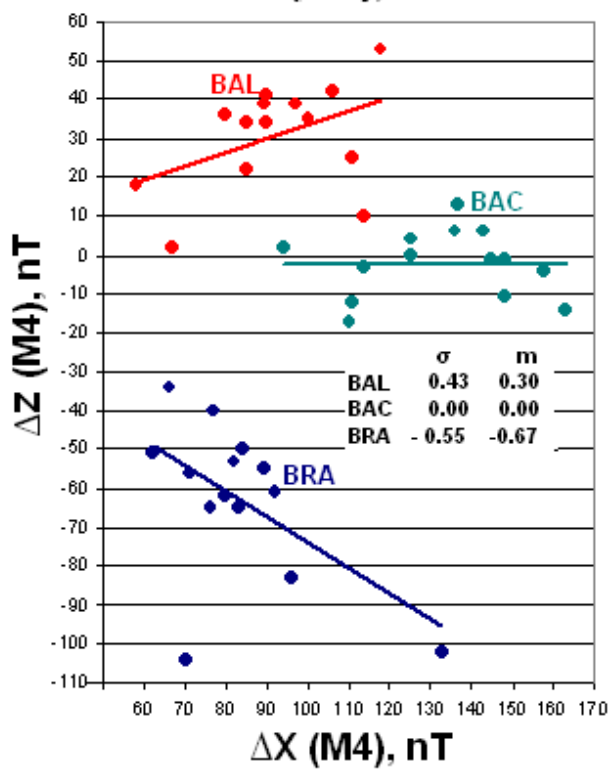

(c)

Fig. 11. Latitudinal profiles of the daily variation of the $\Delta X, \Delta Y$ and $\Delta Z$ components at different hours of the day at East Brazil stations. (a) Relationship with M4 range of $\Delta X$ at BAC on individual days with respect to corresponding M4 ranges of $\triangle X$ at BAL and BRA, M4 $\Delta Z$ at BAL, M3 $\Delta Y$ range at BAC and BRA. (b) Relationship between $\Delta Y(\mathrm{M} 4)$ versus $\Delta X(\mathrm{M} 4)$ at different stations. (c) Relationship between $\Delta Z$ (M4) versus $\Delta X(\mathrm{M} 4)$ for different stations. 


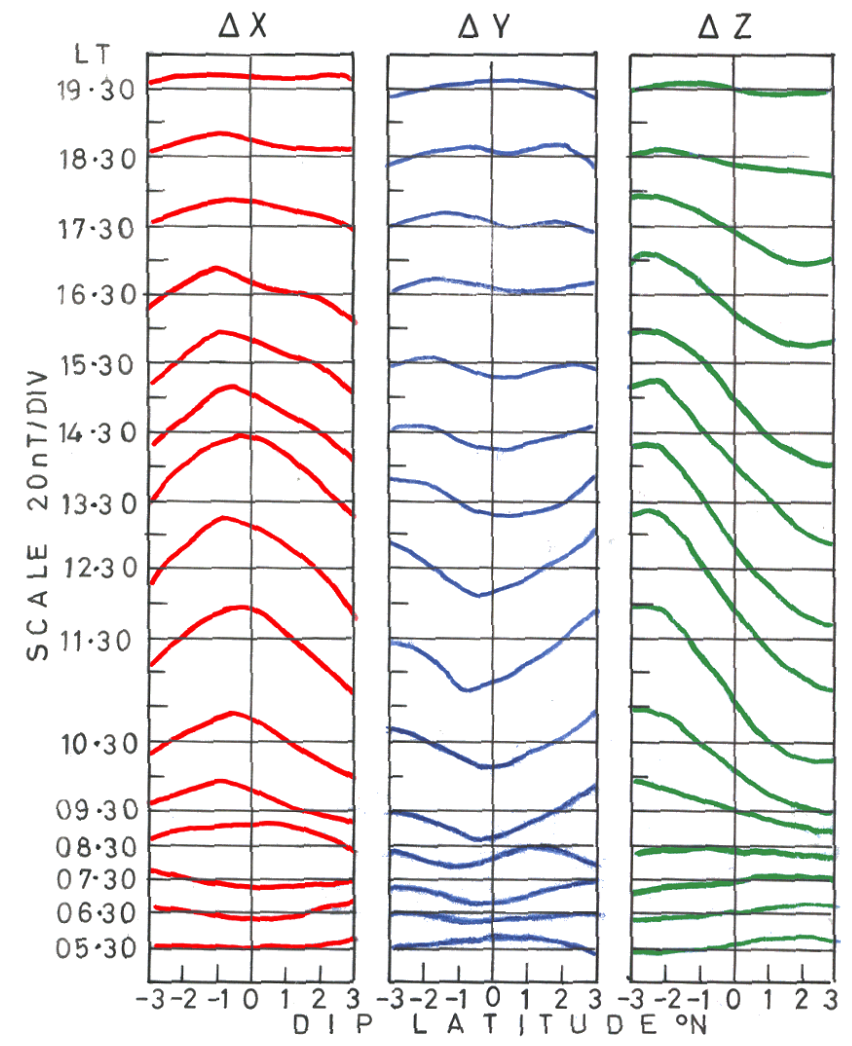

Fig. 12. Mean latitudinal profiles of the regular solar daily variations of $\Delta X, \Delta Y$ and $\Delta Z$ at East Brazilian stations during November 1990 to March 1991.

inter-relationship between $H, D$ and $Z$. It is intriguing why they have not been able to extract regular variations of the Declination in the equatorial electrojet region. Analysis of African data in a similar fashion as the present analysis of Brazilian data is necessary for understanding the latitudinal extent of the south Atlantic magnetic field anomaly.

\section{Discussions}

Next, the various factors affecting the observed magnetic field components due to the equatorial electrojet current and its spatial variations are discussed.

(I) Base line values of the magnetic field components:

The observed hourly mean $\mathrm{H}$ field is the combined effect of various currents at different levels as well as their induced currents inside the Earth, both superimposed over the background main magnetic field. The main magnetic field on any day is estimated from adopted curve drawn through absolute measurements made at intervals of a week or so. It is further assumed that the ionospheric currents are absent or insignificantly small during the night time hours. Subtracting the midnight, or the mean of few hours around midnight from the hourly mean values at other hours is assumed to be indicative of the ionospheric current. Any inconsistency in

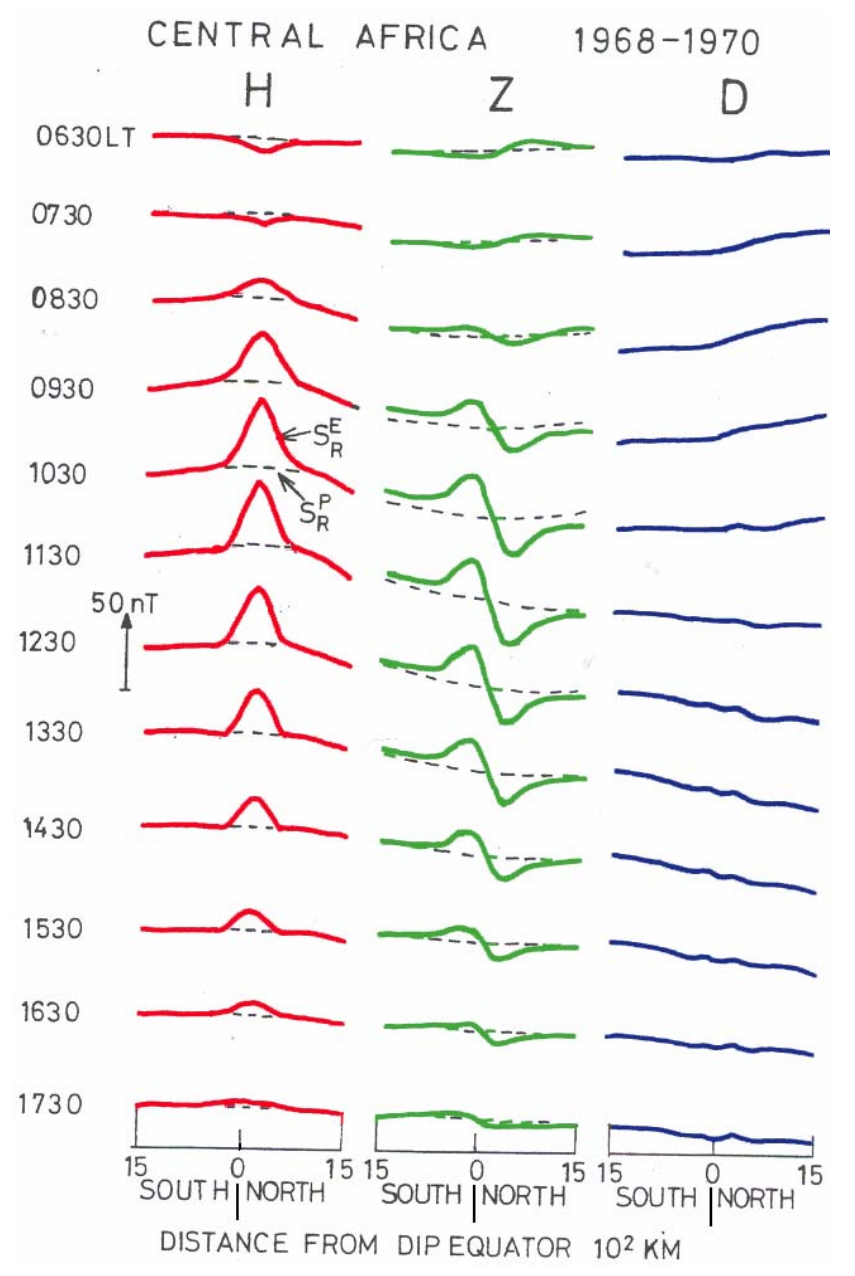

Fig. 13. Variations with geographic latitude of the magnetic field components $\mathrm{H}, \mathrm{Z}$ and $\mathrm{D}$ in $46^{\circ} \mathrm{W}$ geographic longitude sector (after Fambitakoye and Mayaud, 1976).

the consecutive midnight values is corrected by suitably distributing the errors among all the hours (Price and Wilkins, 1963). The hourly deviations of $\Delta H$ at any equatorial or low latitude station is supposed to be zero during the night time hours, starts increasing after the sunrise, reaches its maximum around noon and later decays to the base level $(=0)$ by the sunset. Rastogi and Iyer (1976) showed that during the low sunspot years, the $\mathrm{Sq}(\mathrm{H})$ at an equatorial electrojet station starts increasing at 06:00 LT and returns to the base level by 16:00 LT and remains so throughout the night. During high sunspot years, the $\mathrm{H}$ field continues to decrease from noon to evening and later throughout the night time up to the sunrise, there being no period in the night when the field remains constant.

In Fig. 16 are shown the monthly mean Sq variations of $\Delta X$ at Sao Luiz (SLZ) during the months of January and June 1993. During June 1993, $\Delta X$ was fairly constant between the hours 16:00 LT through the midnight to 07:00 LT 


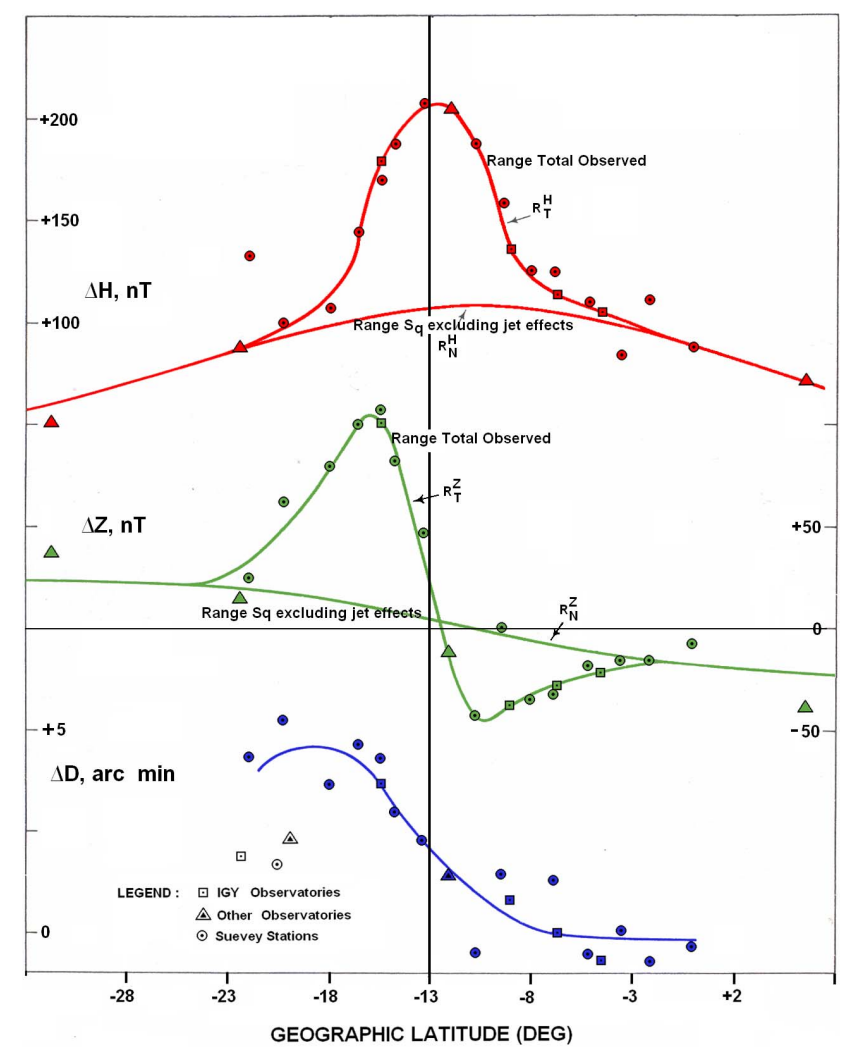

Fig. 14. Latitudinal variations of $\Delta H, \Delta Z$ and $\Delta D$ at $75^{\circ} \mathrm{W}$ longitude sector during International Geophysical Year (after Forbush and Casaverde, 1961).

after which $\Delta X$ increased rapidly due to the rising of the sun. During January 1993, $\Delta X$ continued to decrease after sunset, reached a minimum value around 22:00 LT after which it continued to increase steadily attaining a value of about $20 \mathrm{nT}$ at 06:00 LT after which it increased rapidly due to the production of ionizations by the rising sun. The lower set of curves show the nightly variations of $\Delta X$ on some individual days. On 20-21 January 1993, $\Delta X$ attained minimum value at 21:00-22:00 LT, started increasing slowly till 04:00 LT, after which there was a rapid increase due to the sunrise. On 29-30 March 1993, $\Delta X$ showed a strong depression around 06:30 LT before the rapid increase due to the fresh ionizations in the $\mathrm{E}$ layer. This raises a serious question about the base value of the $\mathrm{X}$ component which has to be assumed when there is no equatorial electrojet current existing.

(ii) The two fundamental parameters which determine the ionospheric current are (a) the peak electron density in the $\mathrm{E}$ region $N m \mathrm{E}$ (or the critical frequency $f o \mathrm{E}\left(\alpha \mathrm{Nm}^{1 / 2}\right)$, (b) the imposed electric field $\zeta$. The E-region is a very well behaved ionospheric layer following Chapman's theory of ionization (Chapman, 1931) and its ionization density is dictated by the solar zenith angle in the diurnal, seasonal and solar cycle variation. Rastogi (1993) studied the diurnal, seasonal and solar cycle variations of $N m \mathrm{E}$ and $\Delta H$ at Kodaikanal, an

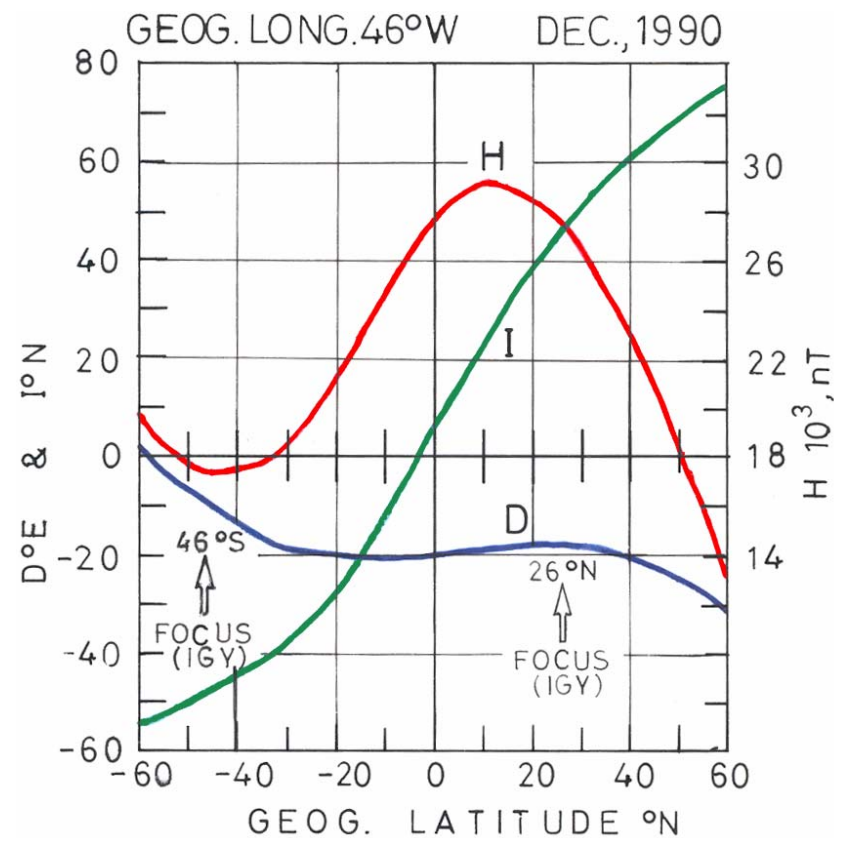

Fig. 15. Variation with geographic latitude of magnetic field components Horizontal field $(H)$, Declination $(D)$ and Inclination $(I)$ along $46^{\circ} \mathrm{W}$ longitude.

equatorial electrojet station for the period 1959-1965. It was shown that the solar cycle variation of the Sq range of $H$ is primarily associated with the E-region electron density with little effect of the electric field variation. The seasonal variation of the range of $H$ is associated with the electric field in the ionosphere with little effect of the variation $N m \mathrm{E}$. The diurnal variation is controlled by the product of both the electron density and the electric field. Electron density reaches a maximum only a few minutes before the local noon and the electric field maximizes at 11:00 LT resulting in the maximum of $\Delta H$ occurring slightly before noon.

The dynamo electric field at any longitude sector depends on the lunar/solar tides in middle atmosphere which are dependent on the orography of the region. The mountain chain in Asia is aligned east-west, while that in American region is an aligned north-south direction. This is bound to affect the global circulation in the upper atmosphere.

Using the program in the website of SPIDR, the magnitude of H, D and I components of the geomagnetic field at different latitudes along the $46 \mathrm{oW}$ longitude were computed. Figure 15 shows the latitudinal variation of the three parameters. It is seen that $H$ was a maximum around $10^{\circ}$ latitude and decreased both northward and southward. Thus, in the east Brazilian sector $H$ decreased rapidly with increasing latitude and was minimum around $40^{\circ} \mathrm{S}$, associated with the South Atlantic Anomaly. This resulted in the centre of Sq current system being $26^{\circ}$ in Northern and $46^{\circ}$ in Southern Hemisphere. The D was around $20^{\circ} \mathrm{W}$ between $30^{\circ} \mathrm{N}$ and $30^{\circ} \mathrm{S}$ latitudes, the largest deviation of magnetic meridian 


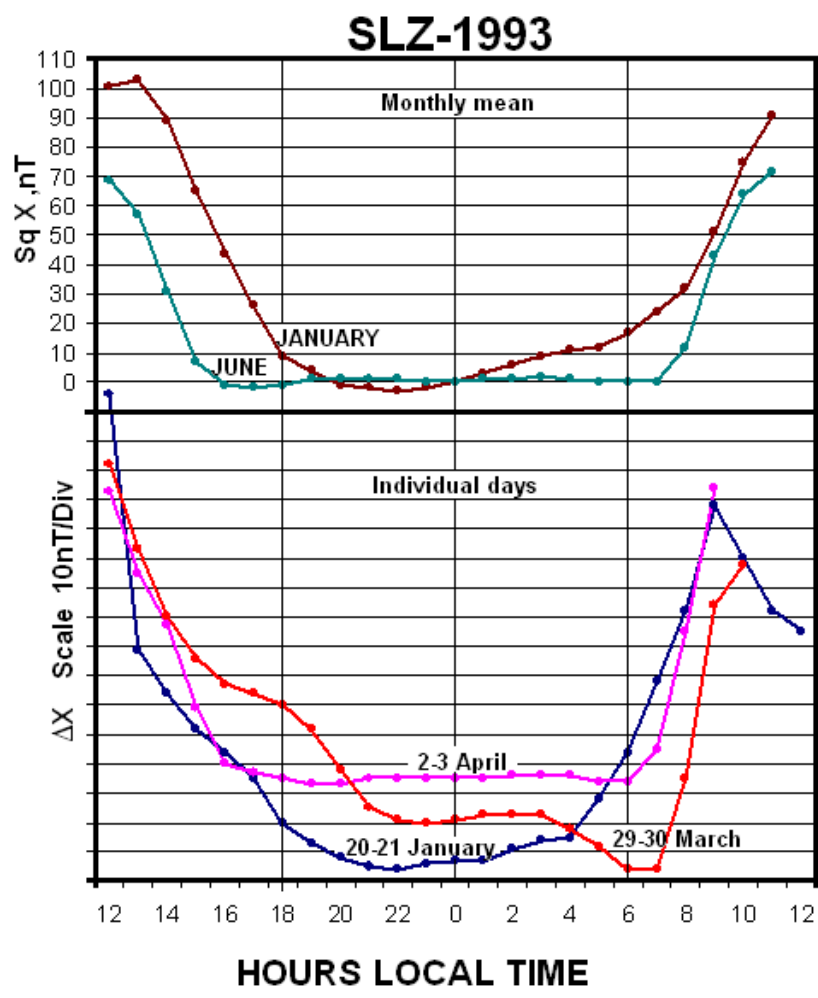

Fig. 16. Daily variations of $\mathrm{SqH}$ at Sao Luiz (SLZ) averaged for January and June 1993 and for individual days 20-21 January, 2930 March and 2-3 April 1993.

from the geographic meridian compared to the same at low latitudes around the world. The Inclination was asymmetries with latitude in this region, increasing slower in south than in the north

These longitudinal non-uniformities in the magnetic field direction and magnitude would seriously affect the movement of ionospheric plasma in the E region and thereby affect the global pattern of the dynamo electric field.

It is concluded, that the longitudinal anomalies in the magnitude or the phase of the daily variation of the equatorial electrojet current is due to longitudinal non-uniformities in the ionospheric electric field rather than due to the longitudinal variations of ionospheric conductivities.

Considering the daily variation of $\Delta H$ at American stations, it has been shown that $\Delta H$ is not constant during the nighttime hours. Hence, there are additional sources of the E region ionizations in American longitudes other than from solar UV and X-ray radiations. These points suggest to the solar charged particle precipitations in the region of a low background magnetic field.

All the models of the equatorial electrojet assume a perfect latitudinal symmetry of the magnetic field components. In the east Brazil sector there is larger north-south asymmetry of the magnetic field. This results a very rapid decrease of current in the north while a very slow variation in the south.
This causes a larger shift of the $\mathrm{Sq}$ focus from the dip equator in the south than in the north.

\section{Suggestions}

First of all it is suggested that a detailed study has to be made using $\mathrm{X}, \mathrm{Y}$ and $\mathrm{Z}$ data from the Brazilian array data for the whole period November 1990 to March 1991 together with those from Tatuoca, Natal and Eusebio and Vassouras.

It is necessary to find out the western and eastern boundaries of the anomaly region. Determination of the direction of current in the $\mathrm{E}$ region of the ionosphere with a $\mathrm{H} \mathrm{F}$ Doppler radar or by spaced receiver drift measurement in $\mathrm{E}$ Brazil would be the most useful method to solve the puzzling problems of the equatorial electrojet and its association with Space Weather. It would be very useful to check the anomaly in Central African longitudes by re-analyzing the earlier data of Fambitakoye.

Any collaborative study of the geomagnetic and ionospheric observations would be very helpful in solving many problems.

Acknowledgements. Thanks are due to Physical Research Laboratory, Ahmedabad and Indian Space Research Organization for infrastructural and financial assistance. Thanks are due to Pathikpal Devadiya for computational assistance. The authors are grateful to the second referee for the suggestions which greatly improved the presentation of the results.

Topical Editor M. Pinnock thanks two anonymous referees for their help in evaluating this paper.

\section{References}

Agarwal, A. K. and Weaver, J. T.: A theoretical study of induction by electrojet over coastline for Sq and sub storm periods, Phys. Earth Planet. Inters. (Netherlands), 61, 165-181, 1990.

Baker, W. J. G. and Martyn, D. F.: Electric currents in the ionosphere 1, the conductivity, Phil. Trans. Roy. Soc. London, A246, 281-294, 1953.

Carlo, L., Singh, B. P., Rastogi, R. G., and Agarwal, A. K.: The induced effect of geomagnetic variations in the electrojet region, J. Geophys., 51, 199-205, 1982.

Carter, D. A., Balsley, B. B., and Eckerlund, W. L.: VHF Doppler radar observatories of the African Equatorial Electrojet, J. Geophys. Res., 81, 2786-2794, 1976.

Chapman, S.: The solar and lunar diurnal variations of terrestrial magnetism, Philos. Trans. Ray. Soc., A218, 1-118, 1919.

Chapman, S.: The absorption and dissociation of ionizing effect of monochromatic radiation in an atmosphere on a rotating Earth, Proc. Phys. Soc. Lond., 43, 26-45, 1931.

Chapman, S.: The equatorial electrojet as detected from the abnormal electric current distribution above Huancayo, Peru and elsewhere, Arch. Meterol. Geophys. Bioklimatol., A4, 368-390, 1951.

Doumbia, V., Maude, A., and Richmond, A. D.: Simulation of equatorial electrojet magnetic effects with the thermosphere 
ionosphere electrodynamics general circulation model, J. Geophys. Res., 112, AO9309, doi:10.1029/207/JA012308, 2007.

Doumouya, V., Vassal, J., Cohen, Y., Fambitakoye, O., and Menvielle, M.: Equatorial electrojet at African longitudes: first results from magnetic measurements, Ann. Geophys., 16, 658666, 1998,

http://www.ann-geophys.net/16/658/1998/.

Egedal, J.: The magnetic diurnal variation of the horizontal force near the magnetic equator, Terr. Magn. Atmos. Electr., 52, 449451, 1947.

Fambitakoye, O. and Mayaud, P. N.: Equatorial electrojet and regular daily variation SR-I. A determination of the equatorial electrojet parameters, J. Atmos. Terr. Phys., 38, 1-17, 1976.

Forbush, S. E. and Casaverde, M.: Equatorial electrojet in Peru, Carnegie Instn., Washington Publication, No. 620, Washington D.C., 1961.

Ivers, D., Stening, R., Turner, J., and Winch, D.: Equatorial electrojet from Ørsted scalar magnetic field observations, J. Geophys. Res., 108(A2), 1061, doi:1029/2002JA009310, 2003.

Jadhav, G., Rajaram, M., and Rajaram, R.: A detailed study of equatorial electrojet phenomenon using Ørsted satellite observations, J. Geophys. Res., 107(A8), 1175, doi:10.1029/2001JA000183, 2002.

James, M. E., Tripathi, D., and Rastogi, R. G.: Day-to-Day variability of ionospheric current system, Ind. J. Rad. Space. Phys., 25, 36-43, 1996.

Lühr, H., Maus, S., and Rother, M.: Noon-time equatorial electrojet: Its spatial features as determined by the CHAMP satellite, J. Geophys. Res., 109, A01306, doi:10.1029/2002JA009656, 2004.

McNish, A. G.: Progress of research in magnetic diurnal variation at the Dept, Terr. Magn. Carnegie. Inst. Washington. Transactions Edinburgh meeting 1936, Int. Union. Geoed. Geophys. Assoc. Terr. Magn. Electr. Bull., 10, 467-518, 1937.

Omwumechilli, C. A.: Geomagnetic variations in the equatorial zone, Physics of the geomagnetic phenomenon, vol. 1, edited by: Matsushita, S. and Campbell, W. H., Academic Press, New York, 425-507, 1967.

Price, A. T. and Wilkins, G. A.: New method for the analysis of geomagnetic fields and their application to Sq field of 1932-33, Phil. Trans. Roy. Soc. Lond., A256, 31-98, 1963.

Rastogi, R. G.: Longitudinal variation in the equatorial electrojet, J. Atmos. Terr. Phys., 24, 1031-1040, 1962.
Rastogi, R. G.: On the simultaneous existence of eastward and westward flowing equatorial electrojet current, Proc. Ind. Acad. Sci., A81, 80-92, 1975.

Rastogi, R. G. and Iyer, K. N.: Quiet day variation of geomagnetic H-field at low latitudes, J. Geom. Geoelectr., 28, 461-479, 1976.

Rastogi, R. G., Fejer, B. G., and Woodman, R. F.: Sudden disappearance of VHF radar echoes from equatorial $E$ region irregularities, Ind. J. Rad. Space, Phys., 6, 39-43, 1977.

Rastogi, R. G.: The equatorial electrojet in magnetic and ionospheric effects in GEOMAGNETISM, 3, 461-525, edited by: Jacobs, J., Academic Press Ltd., 1989.

Rastogi, R. G.: Geomagnetic field variations at low latitudes and ionospheric electric fields, J. Atmos. Terr. Phys., 55(10), 13751381, 1993.

Rastogi, R. G.: Sq and sfe currents at equatorial stations along the western and eastern African sectors, Earth Planet Space, 58, 1475-1478, 2006.

Rigoti, A.: Geomagnetic array study of the EEJ in NE Brazil, Thesis for the degree of Doctor of Philosophy, Flinders University of South Australia, 1994.

Rastogi, R. G., Chandra, H., James, M. E., Kitamura, K., and Ymoto, K.: Characterestics of the equatorial electrojet current in Central region of South America, Earth Planets Space, 60, 623632, 2008.

Rigoti, A., Chamalaun, F. H., Trivedi, N. B., and Padilha, A. L.: Characteristics of the equatorial electrojet determined from an array of magnetometers in N-NG Brazil, Earth Planet and Space, $51,115-128,1999$.

Schuster, A.: The diurnal variation of terrestrial magnetism, Phil. Trans. Roy. Soc. Condon., A180, 467-518, 1889.

Schuster, A.: The diurnal variation of terrestrial magnetism, Phil. Trans. Roy. Soc., A208, 163-208, 1908.

Sugiura, M. and Cain, J. C.: A model equatorial electrojet, J. Geophys. Res., 71, 1869-1877, 1966.

Sugiura, M. and Poros, D. J.: An improved model equatorial electrojet with a meridional current system, J. Geophys. Res., 74, 4025-4034, 1969.

Untiedt, J.: A model of the equatorial electrojet involving meridional currents, J. Geophys. Res., 72, 5799-5810, 1967. 